Article

\title{
Emeralds from the Most Important Occurrences: Chemical and Spectroscopic Data
}

\author{
Stefanos Karampelas * ${ }^{\mathbb{D}}$, Bader Al-Shaybani, Fatima Mohamed, Supharart Sangsawong \\ and Abeer Al-Alawi
}

Bahrain Institute for Pearls \& Gemstones (DANAT), WTC East Tower, P.O. Box 17236 Manama, Bahrain; Bader.Alshaybani@danat.bh (B.A.-S.); Fatima.Mohamed@danat.bh (F.M.);

Supharart.Sangsawong@danat.bh (S.S.); Abeer.Alalawi@danat.bh (A.A.-A.)

* Correspondence: Stefanos.Karampelas@danat.bh; Tel.: +973-1720-1333

Received: 1 August 2019; Accepted: 9 September 2019; Published: 19 September 2019

check for updates

\begin{abstract}
The present study applied LA-ICP-MS on gem-quality emeralds from the most important sources (Afghanistan, Brazil, Colombia, Ethiopia, Madagascar, Russia, Zambia and Zimbabwe). It revealed that emeralds from Afghanistan, Brazil, Colombia and Madagascar have a relatively lower lithium content $\left({ }^{7} \mathrm{Li}<200 \mathrm{ppmw}\right)$ compared to emeralds from other places $\left({ }^{7} \mathrm{Li}>250 \mathrm{ppmw}\right)$. Alkali element contents as well as scandium, manganese, cobalt, nickel, zinc and gallium can further help us in obtaining accurate origin information for these emeralds. UV-Vis spectroscopy can aid in the separation of emeralds from Colombia and Afghanistan from these obtained from the other sources as the latter present pronounced iron-related bands. Intense Type-II water vibrations are observed in the infrared spectra of emeralds from Madagascar, Zambia and Zimbabwe, as well as in some samples from Afghanistan and Ethiopia, which contain higher alkali contents. A band at $2818 \mathrm{~cm}^{-1}$, supposedly attributed to chlorine, was observed only in emeralds from Colombia and Afghanistan. Samples with medium to high alkalis from Ethiopia, Madagascar, Zambia and Zimbabwe can also be separated from the others by Raman spectroscopy based on the lower or equal relative intensity of the Type I water band at around $3608 \mathrm{~cm}^{-1}$ compared to the Type II water band at around $3598 \mathrm{~cm}^{-1}$ band (with some samples from Afghanistan, Brazil and Russia presenting equal relative intensities).
\end{abstract}

Keywords: emeralds; LA-ICP-MS; UV-Vis-NIR; FTIR; Raman; PL

\section{Introduction}

Emeralds, together with rubies and sapphires (red and blue corundum), as well as jadeite "jade" (jadeitite), diamonds and natural pearls, have been the most sought-after gems for several centuries. Emerald is the bluish-green to green to yellowish-green variety of beryl (with an ideal formula of $\mathrm{Be}_{3} \mathrm{Al}_{2} \mathrm{SiO}_{18}$ ) coloured by chromium and/or vanadium (iron may also contribute to the colour, but to a lesser extent); beryl coloured solely by iron is green beryl (and not emerald) [1]. Transparent natural emeralds of homogenous vivid-green colour are the most researched. Most faceted gems are sold by carat $(1$ carat $=0.2 \mathrm{~g}$ ), but their monetary value is not linearly correlated with their weight; bigger gems are rarer and can fetch higher prices. Absence or presence, type and degree of treatment are also important factors linked to gems' monetary value. In the case of emeralds, most gem-quality faceted stones contain surface-reaching fissures and, some of them, also cavities. In order to improve their clarity, the vast majority of emeralds are "filled" with a material having a refractive index similar to that of emerald (oil, resin or other) that reduces the visibility of the fissures and, sometimes, the cavities [2-4]. The degree of emerald clarity enhancement, which is not always directly linked with the amount of filling material, ranges from none to significant, with the former being very rare and more desirable [5]. Geographic origin is frequently requested from gemmological laboratories by customers as it is used 
by gem dealers as a brand name, is sometimes linked with history, exoticism, spirituality, etc., and might play an important role in the monetary value of a gem [6-23]. In parallel, over the last two decades, ethical issues related to gem mining have been in the spotlight, and end consumers demand transparency about the mine-to-market supply chain, in addition to detailed information on stones' provenance [23-26]. Origin determination for gems is also useful for archaeologists, curators, etc., as it can help them to better understand early trade routes [27-40].

Origin determination is based on gem characteristics linked to geological formation. However, gemmological laboratories are asked to issue reports mentioning a gem's geographical origin, which is related to politics rather than geology $[12,15]$. Geographic origin determination is getting more complicated, considering that gems can grow in similar geologic environments but in different countries; e.g., emeralds associated with granites-pegmatites and mafic-ultramafic rocks as in Kafubu, Zambia; Malyshevsk (the Ural Mountains), Russia; Mananjary, Madagascar; etc. In parallel, a gem can grow in more than one geological environment in the same country; e.g., emeralds occur in Zambia in both Kafubu near Kitwe (associated with granites-pegmatites and mafic-ultramafic rocks; Type IA occurrence-see classification below) and Musakashi near Solwezi (in eluvial lateritic soils adjacent to quartz veins; Type IID occurrence-see classification below) [16-19,21,31,41,42].

Emerald is a relatively rare mineral because it needs common elements such as silicon ( $\mathrm{Si}$ ), aluminium $(\mathrm{Al})$ and oxygen $(\mathrm{O})$, together with less common elements (that are rarely encountered together) such as beryllium (Be)—enriched in the crust, chromium ( $\mathrm{Cr}$ - — typically enriched in mantle rocks, and/or vanadium $(\mathrm{V})$, with iron $(\mathrm{Fe})$ in limited concentrations; however, it can be found on all continents except Antarctica [16-18,21]. Emeralds of gem quality and economic importance are not always formed though; several parameters play an important role in gem formation $[43,44]$. It is important to have the right ingredients in just the right amounts (as previously mentioned): favourable "thermobarometric conditions", space to grow (with some exceptions), limited nucleation (i.e., few nuclei will evolve into a crystal) and stable growth conditions for a certain amount of time, but not for millions of years [44]. Importantly, post-growth phenomena that might damage the gem, such as mechanical fracturing, chemical etching, etc., should be absent [43].

A gemmological report with the origin for an emerald from a laboratory recognized by the international market can cost from ca. 100 up to 500 USD for gems $<2$ ct and $>2000$ USD for gems $>50 \mathrm{ct}$, depending on the laboratory. Thus, gemmological laboratories receive principally mediumto high-quality "large" faceted ( $>0.5 \mathrm{ct}$ and mostly $>1 \mathrm{ct}$ ) emeralds "worth" an origin determination report. Nowadays these emeralds mostly come from Colombia (both the east and west side of central Cordillera), Zambia (Kafubu), Brazil (Itabira, Minas Gerais), Russia (Malyshevsk, the Ural mountains), Madagascar (Mananjary), Afghanistan (Panjsher Valley), Zimbabwe (Sandawana) and recently Ethiopia (Shakisso). In terms of monetary value, an emerald from Colombia fetches higher prices than an emerald of exactly the same size and quality from another country. Samples of similar size and quality other than Colombian fetch similar prices, but the traders still ask for an origin to be mentioned in the report.

The classification of emerald deposits is presented in several works, and recently an enhanced classification has been suggested $[13,17,21]$. According to this, the geological environment of the vast majority of occurrences producing gem-quality emeralds is classified as Type IA-tectonicmagmatic-related hosted in mafic-ultramafic rocks [21]. Only emeralds from Colombia are classified as Type IIB; tectonic-metamorphic-related hosted in sedimentary rock-black shale and emeralds from Afghanistan (Panjsher Valley) are classified as Type IIC; tectonic-metamorphic-related are hosted in metamorphic rocks [21].

Gemmological laboratories are issuing reports on emeralds (including origin determination), and coloured gems in general, after combining the results obtained by several methods $[11,12,15,19,20]$. The methods used should be non-destructive and rarely micro-destructive [45-48]. For the origin determination and characterization of emeralds, microscopy, FTIR (Fourier-Transform InfraRed) spectroscopy, UV-Vis-NIR (Ultraviolet-Visible-Near InfraRed) spectroscopy, chemistry such as EDXRF 
(Energy-Dispersive X-ray Spectroscopy), sometimes LA-ICP-MS (Laser Ablation-Inductively Coupled Plasma-Mass Spectrometry) as well as LIBS (Laser-Induced Breakdown Spectroscopy) and, in same cases, Raman and PL (photoluminescence) spectroscopy are used [6,7,11,12,15,19,20,23,31,40-42,49-78]. Oxygen isotopes as well as fluid inclusions are also used for their study (see [21] for more information and further references); however, these methods are currently rarely used by gemmological laboratories. Gem-quality emeralds present some characteristics that might help gemmological laboratories build an accurate database to trace the origin of an unknown sample, in contrast with some other gems which might be more challenging (e.g., sapphires). For instance, the majority of gem-quality emeralds are found in primary deposits [76]; they contain inclusions that are associated with their geology and, due to their crystal structure and chemistry, several minor and trace elements directly linked to their growth environments could be present.

For the present work, 62 samples from eight countries' data were collected using LA-ICP-MS as well as UV-Vis-NIR, FTIR, Raman and PL spectroscopy. The data from the samples were compared, looking for potential differences linked to their geographical origin. This is the first study that combines all these methods on samples from the most important sources of gem-quality emeralds.

\section{Materials and Methods}

All 62 samples studied are listed in Table 1. Forty-three samples were rough, and small areas ("windows") were cut and polished in order to acquire better spectroscopic and chemical data, four of them were oriented (i.e., cut and polished parallel and/or perpendicular to the c-axis) and fifteen were faceted (all from Brazil). Most of the samples studied had a green or dark green homogenous colour. All samples from Russia were light green; some of the samples from Brazil and Colombia were also light green. All samples from Russia presented numerous inclusions.

Table 1. List of studied samples, along with their weight and colour ranges.

\begin{tabular}{cccc}
\hline Locality & No. of Samples & Weight Range (ct) & Colour Range \\
\hline Afghanistan (Panjsher Valley from & 9 & $0.27-0.68$ & Green \\
Kherskanda) & 18 & $0.17-1.88$ & Light green to green \\
Brazil (Itabira) & 8 & $0.11-2.42$ & Light green to green \\
Colombia (Coscuez) & 4 & $0.43-1.69$ & Green \\
Ethiopia (Shakisso) & 9 & $0.17-2.18$ & Green to dark green \\
Madagascar (Mananjary from Irondro, & 5 & $0.33-0.80$ & Light green \\
Ambodivandrika and Morarano) & 6 & $0.47-2.50$ & Green \\
Russia (Malyshevsk, Ural mountains) & 3 & $0.24-0.56$ & Green \\
Zambia (Kafubu) & & & \\
\hline
\end{tabular}

UV-Vis-NIR spectra were acquired using a Cary 5000 UV-Vis-NIR spectrometer (Varian Inc., Palo Alto, CA, USA) in the 250-1500 nm spectral range, with a spectral bandwidth and data interval of $0.7 \mathrm{~nm}$ and a scan rate of $60 \mathrm{~nm} / \mathrm{min}$ for the UV-Vis region and a spectral bandwidth and data interval of $1.0 \mathrm{~nm}$ and a scan rate of $120 \mathrm{~nm} / \mathrm{min}$ for the NIR region. Polarized spectra using a diffraction grating polarizer were acquired on the oriented samples.

FTIR spectra were acquired from 8000 to $300 \mathrm{~cm}^{-1}$ using a Nicolet iS5 spectrometer (Thermo Fischer Scientific, Waltham, MA, USA) with $4 \mathrm{~cm}^{-1}$ resolution and 500 scans (background spectra were collected using the same parameters). Most of the spectra were unpolarized (or partially oriented); i.e., acquired on randomly oriented samples; positioned to maximize the signal. The c-axis of unoriented samples was checked so that none of the spectra were acquired with the beam parallel to the axis.

The absorption coefficient (a) was plotted to all UV-Vis-NIR and FTIR spectra. This was calculated using the formula $a=2.303 \mathrm{~A} / \mathrm{d}$, where $A$ is the absorbance and $d$ is the path length (or sample thickness for measurements on parallel polished windows) in $\mathrm{cm}$.

Raman spectra were acquired using a Renishaw inVia spectrometer (Renishaw plc, Wotton-under-Edge, Gloucestershire, UK) from 100 to $2000 \mathrm{~cm}^{-1}$ and from 3300 to $3950 \mathrm{~cm}^{-1}$, coupled with an optical 
microscope, $514 \mathrm{~nm}$ excitation wavelength (diode-pumped solid-state laser), 1800 grooves/mm grating, notch filter, 40-micron slit, a spectral resolution of around $2 \mathrm{~cm}^{-1}$ and calibrated using a diamond at $1331.8 \mathrm{~cm}^{-1}$. For the $100-2000 \mathrm{~cm}^{-1}$ range, $40 \mathrm{~mW}$ laser power on the sample was used to acquire all Raman spectra (except for one sample from Colombia and one sample from Afghanistan, where a laser power of $8 \mathrm{~mW}$ was used to avoid spectra saturation linked to high sample luminescence), 50× short distance objective lens, an acquisition time of $20 \mathrm{~s}$ and five accumulations. As for the $3300-3950 \mathrm{~cm}^{-1}$ range, laser power of $0.8 \mathrm{~mW}$ on the sample was used to acquire all Raman spectra, $50 \times$ short distance objective lens, an acquisition time of $10 \mathrm{~s}$ (except for one sample from Colombia, where an acquisition time of $5 \mathrm{~s}$ was used) and 60 accumulations (except for the aforementioned sample from Afghanistan, where 40 accumulations were used).

Photoluminescence spectra from 550 to $900 \mathrm{~nm}$ were acquired on the samples using the Raman spectrometer with a $0.04 \mathrm{~mW}$ laser power on the sample, 50× short distance objective lens and an acquisition time of $10 \mathrm{~s}$; different parameters were used for a sample from Afghanistan: $0.00008 \mathrm{~mW}$ laser power and an acquisition time of $20 \mathrm{~s}$. Most spectra were acquired parallel and perpendicular to the samples' c-axis; the c-axis was positioned using a polariscope and a conoscope.

LA-ICP-MS chemical analysis was performed using an iCAPQ (Thermo Fisher Scientific; Waltham, MA, USA) Inductively Coupled Plasma-Mass Spectrometer (ICP-MS) coupled with a Q-switched Nd: YAG Laser Ablation (LA) device operating at a wavelength of $213 \mathrm{~nm}$ (Electro Scientific Industries, Fremont, CA, USA). A laser spot of $40 \mu \mathrm{m}$ in diameter was used, along with a fluence of around $10 \mathrm{~J} / \mathrm{cm}^{2}$ and a $10 \mathrm{~Hz}$ repetition rate. The laser warmup/background time was $20 \mathrm{~s}$, the dwell time was $30 \mathrm{~s}$, and the washout time was $50 \mathrm{~s}$. For the ICP-MS operations, the forward power was set at $\sim 1550 \mathrm{~W}$, the typical nebulizer gas (argon) flow was $\sim 1.0 \mathrm{~L} / \mathrm{min}$ and the carrier gas (helium) set at $\sim 0.80 \mathrm{~L} / \mathrm{min}$. The criteria for the alignment and tuning sequence were to maximize the beryllium (Be) counts and keep the ThO/Th ration below 2\%. NIST 610 and NIST 612 glasses were used for calibration standards. The time-resolved signal was processed in Qtegra ISDS software (version 2.10, Thermo Fisher Scientific; Waltham, MA, USA) using silicon $\left({ }^{29} \mathrm{Si}\right)$ as the internal standard, applying $31.35 \mathrm{wt} \%$ theoretical value for beryl. The limits of detection (LOD) and limits of quantification (LOQ) for each of the abovementioned elements are shown in Table 2. These limits differ from day to day (for every set of measurements), so they are presented as ranges, from the lowest to the highest. Three spots were analysed on every sample and five were analysed on samples from Ethiopia and Zimbabwe. The measured points were checked under a microscope (Nikon, Shinagawa, Tokyo, Japan) to make sure they are on green zones without inclusions (however, the presence of micro-inclusions cannot be completely ruled out).

Table 2. LA-ICP-MS detection limits and ranges in ppmw.

\begin{tabular}{cccccc}
\hline Limits & ${ }^{7} \mathbf{L i}$ & ${ }^{23} \mathbf{N a}$ & ${ }^{24} \mathbf{M g}$ & ${ }^{39} \mathbf{K}$ & ${ }^{45} \mathbf{S c}$ \\
\hline LOD & $0.29-0.87$ & $7.00-49.13$ & $0.28-1.24$ & $6.82-17.72$ & $0.44-1.07$ \\
LOQ & $0.87-2.42$ & $21.00-147.38$ & $0.83-3.73$ & $20.45-53.16$ & $1.32-3.20$ \\
\hline Limits & ${ }^{51} \mathbf{V}$ & ${ }^{52} \mathbf{C r}$ & ${ }^{55} \mathbf{M n}$ & ${ }^{56} \mathbf{F e}$ & ${ }^{59} \mathbf{C o}$ \\
\hline LOD & $0.29-0.85$ & $1.36-1.99$ & $0.23-0.67$ & $4.37-6.51$ & $0.09-0.42$ \\
LOQ & $0.86-2.54$ & $4.07-5.96$ & $0.70-2.01$ & $13.12-19.52$ & $0.28-1.25$ \\
\hline Limits & ${ }^{60} \mathbf{N i}$ & ${ }^{66} \mathbf{Z n}$ & ${ }^{69} \mathbf{G a}$ & ${ }^{85} \mathbf{R b}$ & ${ }^{133} \mathbf{C s}$ \\
\hline LOD & $2.71-6.11$ & $0.65-2.28$ & $0.13-0.45$ & $0.15-0.28$ & $0.02-0.07$ \\
LOQ & $8.12-18.33$ & $1.94-6.85$ & $0.39-1.36$ & $0.44-0.83$ & $0.06-0.21$ \\
\hline \multicolumn{7}{c}{ LOD: Limits of detection; LOQ: Limits of quantification. }
\end{tabular}

The amount of water in emeralds is difficult to measure directly. However, it was found to be linked to $\mathrm{Na}_{2} \mathrm{O}$ concentration [79] and can be calculated using the following equation: $\mathrm{H}_{2} \mathrm{O}$ wt $\%=$ $0.5401 \times \ln \left(\mathrm{Na}_{2} \mathrm{O} w \mathrm{w} \%\right)+2.1867[80]$. 


\section{Results and Discussion}

\section{1. $L A-I C P-M S$}

LA-ICP-MS data on the studied samples are presented in Table 3 and all acquired individual chemical analysis are presented in Tables S1-S8. ${ }^{23} \mathrm{Na}$ (sodium) and ${ }^{24} \mathrm{Mg}$ (magnesium) are the most abundant of the minor and trace elements measured in the studied samples, with all studied samples from Zimbabwe (Sandawana) having $\mathrm{Na}_{2} \mathrm{O}>2 \mathrm{wt} \%$. It has been suggested that a $\mathrm{Na}_{2} \mathrm{O}$ content of emeralds $<1 \mathrm{wt} \%$ is considered low, 1 wt $\%<$ medium $<2$ wt $\%$ and $>2$ wt $\%$ high [56]. The studied emeralds from Colombia had a relatively low $\mathrm{Na}_{2} \mathrm{O}$ content. The samples from Afghanistan, Russia and Brazil had relatively low to medium $\mathrm{Na}_{2} \mathrm{O}$ content, with those from Brazil having a medium sodium content as well as most of the studied samples from Afghanistan. Relatively medium to high, and fairly high, sodium quantities were presented by the samples from Ethiopia, Madagascar, Zambia and Zimbabwe, with the latter exhibiting the highest content amongst the studied samples. The calculated water content of the studied samples is listed in Table 3; the Colombian samples presented the lowest calculated water content (1.69-2.17\%), followed by Russian samples (1.99-2.3\%), samples from Brazil (2.17-2.47\%) and samples from Afghanistan, with calculated water content ranging from low (1.93\%) to relatively high $(2.54 \%)$. The vast majority of the other studied samples presented a water content $>2.5 \%$. The plot of $\mathrm{MgO}$ vs. $\mathrm{Na}_{2} \mathrm{O}$ presents a positive correlation (Figure 1), with a $\mathrm{Na}_{2} \mathrm{O} / \mathrm{MgO}$ ratio being below 1 for most of the studied samples; only the studied Russian samples presented a ratio $>1$, with a 1.33 median and a 1.34 average (see Table 3). Data of samples from Brazil, Russia, Zimbabwe, Zambia and Madagascar are similar to previously published data measured with a microprobe $[52,55-57,77]$; some of the Russian emeralds were found to contain higher $\mathrm{MgO}$ with a $\mathrm{Na}_{2} \mathrm{O} / \mathrm{MgO}$ ratio $<1$ [55].

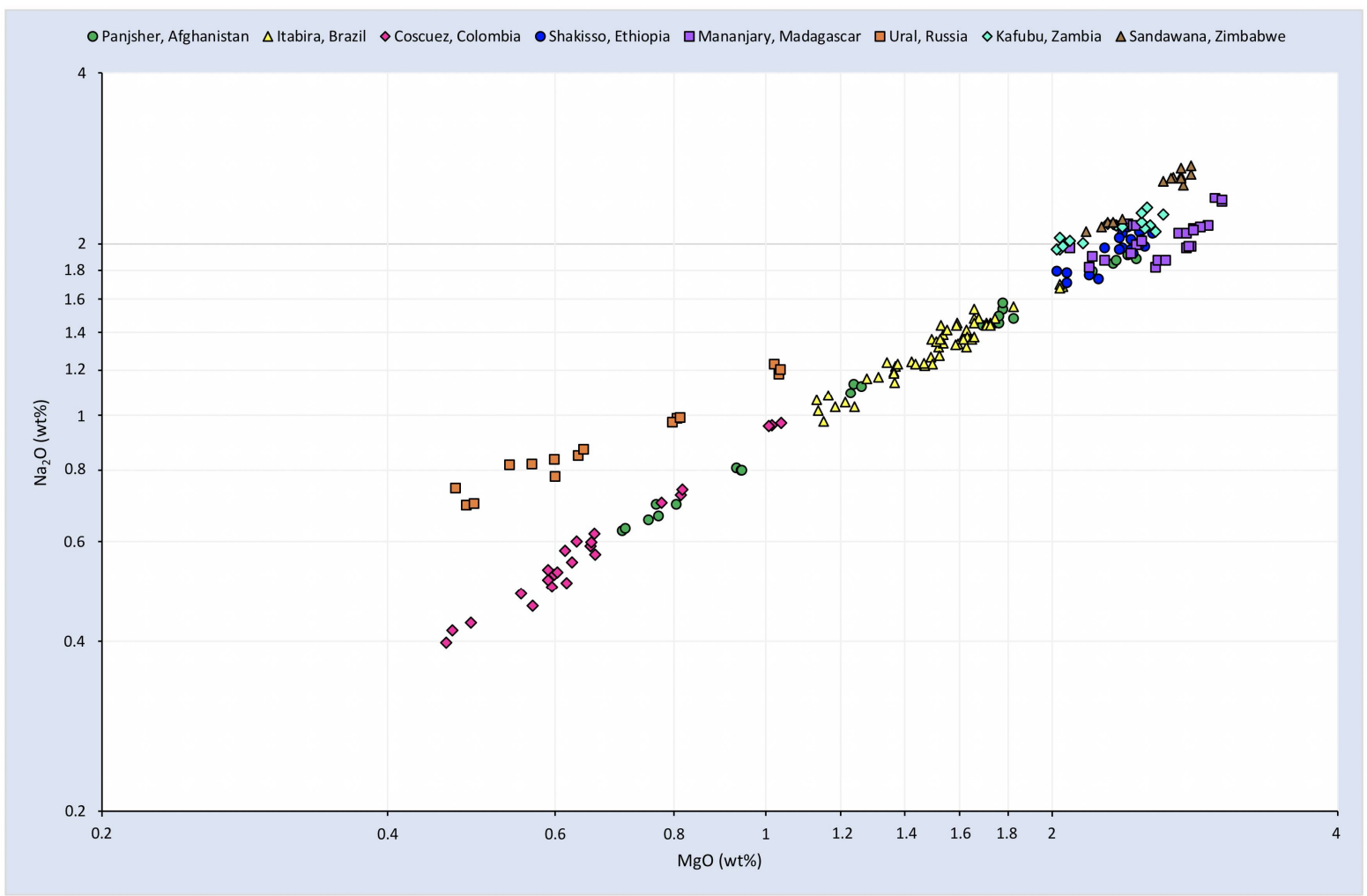

Figure 1. Binary plot of $\mathrm{MgO}(w t \%)$ vs. $\mathrm{Na}_{2} \mathrm{O}$ (wt \%). 
Table 3. LA-ICP-MS of the samples in ppmw.

\begin{tabular}{|c|c|c|c|c|}
\hline Samples & Element & Min-Max & Average (SD) & Median \\
\hline \multirow{19}{*}{$\begin{array}{l}\text { Afghanistan (Panjsher) } \\
9 \text { samples, } 27 \text { analysis }\end{array}$} & ${ }^{7} \mathrm{Li}$ & $84.9-162$ & $115.81(25.86)$ & 108 \\
\hline & $\mathrm{Na}_{2} \mathrm{O}(\%)$ & $0.63-1.91$ & $1.27(0.46)$ & 1.44 \\
\hline & $\mathrm{MgO}(\%)$ & $0.71-2.45$ & $1.51(0.60)$ & 1.69 \\
\hline & ${ }^{39} \mathrm{~K}$ & $107-1540$ & 713.63 (497.38) & 710 \\
\hline & ${ }^{45} \mathrm{Sc}$ & $148-2390$ & 669.07 (782.41) & 256 \\
\hline & ${ }^{51} \mathrm{~V}$ & $557-3130$ & $1312.48(766.18)$ & 1100 \\
\hline & ${ }^{52} \mathrm{Cr}$ & $500-3840$ & $1994.26(1257.28)$ & 2160 \\
\hline & ${ }^{55} \mathrm{Mn}$ & BQL-3.09 & $0.78(1.02)$ & $\mathrm{BQL}$ \\
\hline & ${ }^{56} \mathrm{Fe}$ & $781-2530$ & $1394.70(550.92)$ & 1270 \\
\hline & ${ }^{59} \mathrm{Co}$ & $\mathrm{BQL}^{* *}$ & BQL & BQL \\
\hline & ${ }^{60} \mathrm{Ni}$ & $\mathrm{BQL}$ & BQL & $\mathrm{BQL}$ \\
\hline & ${ }^{66} \mathrm{Zn}$ & $\widehat{B Q L}$ & $\widehat{B Q L}$ & $\widehat{B Q L}$ \\
\hline & ${ }^{69} \mathrm{Ga}$ & $10.1-28.7$ & $17.17(6.04)$ & 14.8 \\
\hline & ${ }^{85} \mathrm{Rb}$ & $11-97.50$ & $48.90(30.84)$ & 46.40 \\
\hline & ${ }^{133} \mathrm{Cs}$ & $22.1-75.9$ & $40.11(14.98)$ & 41.6 \\
\hline & ${ }^{52} \mathrm{Cr} /{ }^{51} \mathrm{~V}$ & $0.83-2.64$ & $1.47(0.59)$ & 1.20 \\
\hline & $\mathrm{Na}_{2} \mathrm{O} / \mathrm{MgO}(\%)$ & $0.77-0.92$ & $0.85(0.04)$ & 0.85 \\
\hline & Alkalis* $(\%)$ & $0.49-1.61$ & $1.03(0.40)$ & 1.16 \\
\hline & $\mathrm{H}_{2} \mathrm{O}(\%)$ & $1.93-2.54$ & $2.28(0.22)$ & 2.38 \\
\hline \multirow{19}{*}{$\begin{array}{c}\text { Brazil (Itabira) } \\
18 \text { samples, } 54 \text { analysis }\end{array}$} & ${ }^{7} \mathrm{Li}$ & $45.90-97.30$ & $64.11(14.60)$ & 59.90 \\
\hline & $\mathrm{Na}_{2} \mathrm{O}(\%)$ & $0.97-1.70$ & $1.32(0.17)$ & 1.34 \\
\hline & $\mathrm{MgO}(\%)$ & $1.13-2.06$ & $1.53(0.21)$ & 1.53 \\
\hline & ${ }^{39} \mathrm{~K}$ & $152-385$ & $246.83(65.60)$ & 239.50 \\
\hline & ${ }^{45} \mathrm{Sc}$ & $17.5-153$ & $60.3(31.47)$ & 51.15 \\
\hline & ${ }^{51} \mathrm{~V}$ & $52.50-177$ & $116.52(32.72)$ & 117.50 \\
\hline & ${ }^{52} \mathrm{Cr}$ & $997-5700$ & $2508.46(1051.82)$ & 2360 \\
\hline & ${ }^{55} \mathrm{Mn}$ & $4.49-24.10$ & $14.10(5.67)$ & 13.40 \\
\hline & ${ }^{56} \mathrm{Fe}$ & $4540-8760$ & 6407.59 (1122.38) & 6220 \\
\hline & ${ }^{59} \mathrm{Co}$ & $1.94-2.96$ & $2.47(0.30)$ & 2.47 \\
\hline & ${ }^{60} \mathrm{Ni}$ & BQL & BQL & $\mathrm{BQL}$ \\
\hline & ${ }^{66} \mathrm{Zn}$ & $28.40-87.40$ & $55.31(12.31)$ & 57.20 \\
\hline & ${ }^{69} \mathrm{Ga}$ & $6.68-13.80$ & $11.42(1.73)$ & 11.90 \\
\hline & ${ }^{85} \mathrm{Rb}$ & $19.10-52.60$ & $32.73(8.16)$ & 31.25 \\
\hline & ${ }^{133} \mathrm{Cs}$ & $35.50-128$ & $75.52(23.10)$ & 76.85 \\
\hline & ${ }^{52} \mathrm{Cr} /{ }^{51} \mathrm{~V}$ & $8.30-39.45$ & $21.93(7.03)$ & 21.05 \\
\hline & $\mathrm{Na}_{2} \mathrm{O} / \mathrm{MgO}(\%)$ & $0.81-0.94$ & $0.87(0.03)$ & 0.87 \\
\hline & Alkalis* $(\%)$ & $0.75-1.30$ & $1.02(0.13)$ & 1.05 \\
\hline & $\mathrm{H}_{2} \mathrm{O}(\%)$ & $2.17-2.47$ & $2.33(0.07)$ & 2.35 \\
\hline \multirow{19}{*}{$\begin{array}{c}\text { Colombia (Coscuez) } \\
8 \text { samples, } 24 \text { analysis }\end{array}$} & ${ }^{7} \mathrm{Li}$ & $62-163$ & $87.20(35.04)$ & 69.10 \\
\hline & $\mathrm{Na}_{2} \mathrm{O}(\%)$ & $0.40-0.97$ & $0.60(0.16)$ & 0.56 \\
\hline & $\mathrm{MgO}(\%)$ & $0.46-1.04$ & $0.67(0.16)$ & 0.62 \\
\hline & ${ }^{39} \mathrm{~K}$ & BQL & BQL & BQL \\
\hline & ${ }^{45} \mathrm{Sc}$ & $9.17-441$ & 120.14 (135.30) & 56.90 \\
\hline & ${ }^{51} \mathrm{~V}$ & $879-6340$ & $2530.92(1724.94)$ & 2175 \\
\hline & ${ }^{52} \mathrm{Cr}$ & $240-2820$ & $800.71(788.24)$ & 432 \\
\hline & ${ }^{55} \mathrm{Mn}$ & BQL & BQL & $\mathrm{BQL}$ \\
\hline & ${ }^{56} \mathrm{Fe}$ & $507-1860$ & $902.71(493.08)$ & 683 \\
\hline & ${ }^{59} \mathrm{Co}$ & BQL & BQL & BQL \\
\hline & ${ }^{60} \mathrm{Ni}$ & $\mathrm{BQL}$ & $\mathrm{BQL}$ & $\mathrm{BQL}$ \\
\hline & ${ }^{66} \mathrm{Zn}$ & $\mathrm{BQL}$ & $\mathrm{BQL}$ & $\mathrm{BQL}$ \\
\hline & ${ }^{69} \mathrm{Ga}$ & $25.7-58.5$ & $39.30(11.82)$ & 33.95 \\
\hline & ${ }^{85} \mathrm{Rb}$ & $0.79-2.52$ & $1.31(0.48)$ & 1.12 \\
\hline & ${ }^{133} \mathrm{Cs}$ & $4.83-12.1$ & $8.54(2.47)$ & 8.31 \\
\hline & ${ }^{52} \mathrm{Cr} /{ }^{51} \mathrm{~V}$ & $0.12-0.45$ & $0.31(0.09)$ & 0.31 \\
\hline & $\mathrm{Na}_{2} \mathrm{O} / \mathrm{MgO}(\%)$ & $0.81-0.95$ & $0.89(0.04)$ & 0.89 \\
\hline & Alkalis* (\%) & $0.30-0.73$ & $0.46(0.12)$ & 0.43 \\
\hline & $\mathrm{H}_{2} \mathrm{O}(\%)$ & $1.69-2.17$ & $1.90(0.13)$ & 1.87 \\
\hline
\end{tabular}


Table 3. Cont.

\begin{tabular}{|c|c|c|c|c|}
\hline Samples & Element & Min-Max & Average (SD) & Median \\
\hline \multirow{19}{*}{$\begin{array}{c}\text { Ethiopia (Shakisso) } \\
4 \text { samples, } 20 \text { analysis }\end{array}$} & ${ }^{7} \mathrm{Li}$ & $271-427$ & 345.65 (51.78) & 334.50 \\
\hline & $\mathrm{Na}_{2} \mathrm{O}(\%)$ & $1.71-2.16$ & $1.96(0.14)$ & 1.97 \\
\hline & $\mathrm{MgO}(\%)$ & $2.02-2.55$ & $2.34(0.15)$ & 2.37 \\
\hline & ${ }^{39} \mathrm{~K}$ & $290-444$ & 374.45 (52.77) & 371.50 \\
\hline & ${ }^{45} \mathrm{Sc}$ & $57-150$ & $114.30(34.50)$ & 125.50 \\
\hline & ${ }^{51} \mathrm{~V}$ & $96.30-123$ & $112.70(8.10)$ & 114.50 \\
\hline & ${ }^{52} \mathrm{Cr}$ & $2000-5010$ & $3655(1060)$ & 3795 \\
\hline & ${ }^{55} \mathrm{Mn}$ & $9-21.1$ & $16.51(4.22)$ & 18.30 \\
\hline & ${ }^{56} \mathrm{Fe}$ & $3980-5390$ & $4867(507.64)$ & 5050 \\
\hline & ${ }^{59} \mathrm{Co}$ & $1.27-2.20$ & $1.65(0.19)$ & 1.65 \\
\hline & ${ }^{60} \mathrm{Ni}$ & BQL-14.4 & $3.32(5.91)$ & BQL \\
\hline & ${ }^{66} \mathrm{Zn}$ & $32.20-44.80$ & $37.10(3.27)$ & 36.40 \\
\hline & ${ }^{69} \mathrm{Ga}$ & $16.40-20.50$ & $18.77(1.18)$ & 19.15 \\
\hline & ${ }^{85} \mathrm{Rb}$ & $50.60-64.70$ & $57.47(4.58)$ & 57.95 \\
\hline & ${ }^{133} \mathrm{Cs}$ & $270-427$ & $347.50(58.82)$ & 341.50 \\
\hline & ${ }^{52} \mathrm{Cr} /{ }^{51} \mathrm{~V}$ & $19.80-43.66$ & $32.08(8.26)$ & 32.95 \\
\hline & $\mathrm{Na}_{2} \mathrm{O} / \mathrm{MgO}(\%)$ & $0.78-0.92$ & $0.84(0.04)$ & 0.83 \\
\hline & Alkalis* (\%) & $1.38-1.71$ & $1.57(0.10)$ & 1.59 \\
\hline & $\mathrm{H}_{2} \mathrm{O}(\%)$ & $2.48-2.60$ & $2.55(0.04)$ & 2.55 \\
\hline \multirow{19}{*}{$\begin{array}{c}\text { Madagascar } \\
\text { (Mananjary) } \\
9 \text { samples, } 27 \text { analysis }\end{array}$} & ${ }^{7} \mathrm{Li}$ & $57.50-128$ & 98.45 (19.47) & 104 \\
\hline & $\mathrm{Na}_{2} \mathrm{O}(\%)$ & $1.82-2.41$ & $2.05(0.16)$ & 2.01 \\
\hline & $\mathrm{MgO}(\%)$ & $2.07-3.02$ & $2.58(0.30)$ & 2.59 \\
\hline & ${ }^{39} \mathrm{~K}$ & $314-3150$ & $1388.74(808.89)$ & 1090 \\
\hline & ${ }^{45} \mathrm{Sc}$ & $21-309$ & $75.59(86.47)$ & 34.50 \\
\hline & ${ }^{51} \mathrm{~V}$ & $102-386$ & 224.85 (96.63) & 229 \\
\hline & ${ }^{52} \mathrm{Cr}$ & $1490-3770$ & 2380.37 (737.41) & 2410 \\
\hline & ${ }^{55} \mathrm{Mn}$ & $8.65-28.50$ & $15.22(5.56)$ & 15.30 \\
\hline & ${ }^{56} \mathrm{Fe}$ & $7310-11200$ & $9824.81(1131.24)$ & 10,100 \\
\hline & ${ }^{59} \mathrm{Co}$ & $1.69-4.50$ & $3.17(0.70)$ & 3 \\
\hline & ${ }^{60} \mathrm{Ni}$ & $18.10-38.60$ & $28.94(6.30)$ & 30.60 \\
\hline & ${ }^{66} \mathrm{Zn}$ & $9.06-32$ & $16.59(6.65)$ & 15.10 \\
\hline & ${ }^{69} \mathrm{Ga}$ & $6.13-13.10$ & $8.15(1.98)$ & 7.72 \\
\hline & ${ }^{85} \mathrm{Rb}$ & $42.70-407$ & $167.10(106.29)$ & 175 \\
\hline & ${ }^{133} \mathrm{Cs}$ & $105-1050$ & $430(297.51)$ & 324 \\
\hline & ${ }^{52} \mathrm{Cr} /{ }^{51} \mathrm{~V}$ & $4.49-22.54$ & $12.45(5.90)$ & 10 \\
\hline & $\mathrm{Na}_{2} \mathrm{O} / \mathrm{MgO}(\%)$ & $0.71-0.97$ & $0.80(0.08)$ & 0.80 \\
\hline & Alkalis* $(\%)$ & $1.46-1.92$ & $1.73(0.13)$ & 1.77 \\
\hline & $\mathrm{H}_{2} \mathrm{O}(\%)$ & $2.51-2.66$ & $2.57(0.04)$ & 2.56 \\
\hline \multirow{19}{*}{$\begin{array}{c}\text { Russia (Ural) } \\
5 \text { samples, } 15 \text { analysis }\end{array}$} & ${ }^{7} \mathrm{Li}$ & $736-911$ & $826.93(60.19)$ & 831 \\
\hline & $\mathrm{Na}_{2} \mathrm{O}(\%)$ & $0.70-1.23$ & $0.91(0.18)$ & 0.85 \\
\hline & $\mathrm{MgO}(\%)$ & $0.47-1.04$ & $0.70(0.20)$ & 0.64 \\
\hline & ${ }^{39} \mathrm{~K}$ & BQL-103 & 40.87 (41.97) & 52 \\
\hline & ${ }^{45} \mathrm{Sc}$ & $19.50-72.90$ & 43.52 (21.93) & 44.20 \\
\hline & ${ }^{51} \mathrm{~V}$ & 29.80-128 & $80.64(37.30)$ & 90.90 \\
\hline & ${ }^{52} \mathrm{Cr}$ & $318-1700$ & $905.27(446.14)$ & 841 \\
\hline & ${ }^{55} \mathrm{Mn}$ & $13.50-22.60$ & $19.16(3.24)$ & 20.60 \\
\hline & ${ }^{56} \mathrm{Fe}$ & $1210-1900$ & $1600.67(235.75)$ & 1640 \\
\hline & ${ }^{59} \mathrm{Co}$ & BQL-2.09 & $1.08(0.73)$ & 1.19 \\
\hline & ${ }^{60} \mathrm{Ni}$ & BQL-23.20 & $12.90(8.35)$ & 16 \\
\hline & ${ }^{66} \mathrm{Zn}$ & $38.10-62.60$ & $48.62(7.97)$ & 45.40 \\
\hline & ${ }^{69} \mathrm{Ga}$ & $6.28-19.50$ & $13.69(4.40)$ & 13.70 \\
\hline & ${ }^{85} \mathrm{Rb}$ & $7.88-27.20$ & $17.46(7.61)$ & 16.30 \\
\hline & ${ }^{133} \mathrm{Cs}$ & $252-568$ & $350.53(112.54)$ & 308 \\
\hline & ${ }^{52} \mathrm{Cr} /{ }^{51} \mathrm{~V}$ & $6.57-16.13$ & $11.79(3.27)$ & 11.86 \\
\hline & $\mathrm{Na}_{2} \mathrm{O} / \mathrm{MgO}(\%)$ & $1.15-1.58$ & $1.33(0.13)$ & 1.34 \\
\hline & Alkalis* (\%) & $0.65-1.04$ & $0.80(0.13)$ & 0.75 \\
\hline & $\mathrm{H}_{2} \mathrm{O}(\%)$ & $1.99-2.30$ & $2.13(0.10)$ & 2.10 \\
\hline
\end{tabular}


Table 3. Cont.

\begin{tabular}{|c|c|c|c|c|}
\hline Samples & Element & Min-Max & Average (SD) & Median \\
\hline \multirow{19}{*}{$\begin{array}{c}\text { Zambia (Kafubu) } \\
6 \text { samples, } 18 \text { analysis }\end{array}$} & ${ }^{7} \mathrm{Li}$ & $492-741$ & 639.17 (76.19) & 661 \\
\hline & $\mathrm{Na}_{2} \mathrm{O}(\%)$ & $1.95-2.32$ & $2.12(0.11)$ & 2.14 \\
\hline & $\mathrm{MgO}(\%)$ & $2.02-2.62$ & $2.32(0.21)$ & 2.35 \\
\hline & ${ }^{39} \mathrm{~K}$ & $376-716$ & $508.50(121.79)$ & 451 \\
\hline & ${ }^{45} \mathrm{Sc}$ & $19.80-63.40$ & $41.63(13.94)$ & 44.25 \\
\hline & ${ }^{51} \mathrm{~V}$ & $79.30-147$ & $112.82(24.87)$ & 113.15 \\
\hline & ${ }^{52} \mathrm{Cr}$ & $349-2360$ & $1430.94(760.72)$ & 1680 \\
\hline & ${ }^{55} \mathrm{Mn}$ & $11-32.30$ & $22.52(7.95)$ & 24.70 \\
\hline & ${ }^{56} \mathrm{Fe}$ & $6320-9590$ & 8239.44 (932.06) & 8440 \\
\hline & ${ }^{59} \mathrm{Co}$ & $2.23-3.26$ & $2.81(0.31)$ & 2.82 \\
\hline & ${ }^{60} \mathrm{Ni}$ & BQL-28.40 & $20.02(6.30)$ & 19.95 \\
\hline & ${ }^{6} \mathrm{Zn}$ & $17.20-46.60$ & $31.75(10.54)$ & 35.40 \\
\hline & ${ }^{69} \mathrm{Ga}$ & 11.90-17.10 & $14.84(1.56)$ & 14.90 \\
\hline & ${ }^{85} \mathrm{Rb}$ & $41.40-87.30$ & $62.99(16.16)$ & 63.90 \\
\hline & ${ }^{133} \mathrm{Cs}$ & 941-1410 & $1201.72(148.15)$ & 1215 \\
\hline & ${ }^{52} \mathrm{Cr} /{ }^{51} \mathrm{~V}$ & $3.82-25.38$ & $13.20(7.75)$ & 13.92 \\
\hline & $\mathrm{Na}_{2} \mathrm{O} / \mathrm{MgO}(\%)$ & $0.82-1.00$ & $0.92(0.05)$ & 0.92 \\
\hline & Alkalis* (\%) & $1.67-1.94$ & $1.81(0.08)$ & 1.83 \\
\hline & $\mathrm{H}_{2} \mathrm{O}(\%)$ & $2.55-2.64$ & $2.59(0.03)$ & 2.60 \\
\hline \multirow{19}{*}{$\begin{array}{c}\text { Zimbabwe } \\
\text { (Sandawana) } \\
3 \text { samples, } 15 \text { analysis }\end{array}$} & ${ }^{7} \mathrm{Li}$ & $512-1050$ & $818.20(214.17)$ & 930 \\
\hline & $\mathrm{Na}_{2} \mathrm{O}(\%)$ & $2.10-2.75$ & $2.48(0.24)$ & 2.62 \\
\hline & $\mathrm{MgO}(\%)$ & $2.17-2.80$ & $2.58(0.23)$ & 2.69 \\
\hline & ${ }^{39} \mathrm{~K}$ & $230-434$ & $354.73(86.32)$ & 407 \\
\hline & ${ }^{45} \mathrm{Sc}$ & $16.90-26.80$ & $20.85(3.92)$ & 18.80 \\
\hline & ${ }^{51} \mathrm{~V}$ & $185-280$ & $219.27(38.75)$ & 198 \\
\hline & ${ }^{52} \mathrm{Cr}$ & $1430-2070$ & $1790(237.25)$ & 1770 \\
\hline & ${ }^{55} \mathrm{Mn}$ & 47-93 & $62.85(17.52)$ & 53.40 \\
\hline & ${ }^{56} \mathrm{Fe}$ & $4320-7050$ & $6062.67(1170.14)$ & 6810 \\
\hline & ${ }^{59} \mathrm{Co}$ & $1.98-2.55$ & $2.26(0.17)$ & 2.25 \\
\hline & ${ }^{60} \mathrm{Ni}$ & BQL-19.70 & $14.67(5.36)$ & 16.60 \\
\hline & ${ }^{66} \mathrm{Zn}$ & $72.90-84.70$ & $79.49(3.49)$ & 79.30 \\
\hline & ${ }^{69} \mathrm{Ga}$ & $24.80-33.70$ & $28.37(3.28)$ & 27 \\
\hline & ${ }^{85} \mathrm{Rb}$ & 217-299 & $263.47(32.29)$ & 279 \\
\hline & ${ }^{133} \mathrm{Cs}$ & $274-756$ & $589.07(224.06)$ & 739 \\
\hline & ${ }^{52} \mathrm{Cr} /{ }^{51} \mathrm{~V}$ & $7.32-10.05$ & $8.25(0.85)$ & 8.14 \\
\hline & $\mathrm{Na}_{2} \mathrm{O} / \mathrm{MgO}(\%)$ & $0.93-1.00$ & $0.96(0.02)$ & 0.96 \\
\hline & Alkalis* (\%) & $1.68-2.29$ & $2.04(0.23)$ & 2.18 \\
\hline & $\mathrm{H}_{2} \mathrm{O}(\%)$ & $2.59-2.73$ & $2.67(0.05)$ & 2.71 \\
\hline
\end{tabular}

* Alkalis: ${ }^{7} \mathrm{Li}+{ }^{23} \mathrm{Na}+{ }^{39} \mathrm{~K}+{ }^{85} \mathrm{Rb}+{ }^{133} \mathrm{Cs}$; ${ }^{* *} \mathrm{BQL}$ : Below Quantification Limits.

Chemical elements responsible for the colour of emeralds, such as $\mathrm{Cr}, \mathrm{V}$ and $\mathrm{Fe}$, can be seen in various amounts (e.g., ${ }^{56} \mathrm{Fe}$ up to $11200 \mathrm{ppmw}$ for a sample from Madagascar). $\mathrm{The}{ }^{52} \mathrm{Cr} /{ }^{51} \mathrm{~V}$ ratio vs. ${ }^{56} \mathrm{Fe}$ is represented in Figure 2. The ${ }^{52} \mathrm{Cr} /{ }^{51} \mathrm{~V}$ ratio is $>3.8$ for all studied Type IA samples. All studied samples from Colombia presented ${ }^{52} \mathrm{Cr}<{ }^{51} \mathrm{~V}$, with a ${ }^{52} \mathrm{Cr} /{ }^{51} \mathrm{~V}$ ratio ranging from 0.12 to 0.45 . Only two of the nine studied samples from Afghanistan presented ${ }^{52} \mathrm{Cr} /{ }^{51} \mathrm{~V}<1$, while the other studied samples had ratios reaching up to 2.64 (see Table 3 and Figure 2). The distribution and scattering of the analysed points in Figure 2 might be influenced by the colour of the analysed samples (e.g., all samples from Russia were light green in colour).

Alkali metals, other than ${ }^{23} \mathrm{Na}$, are also present in emeralds in different concentrations $\left(\mathrm{see}^{7} \mathrm{Li}^{7},{ }^{39} \mathrm{~K}\right.$, ${ }^{85} \mathrm{Rb}$ and ${ }^{133} \mathrm{Cs}$ in Table 3). The sum of the concentrations of all alkali metals $\left({ }^{7} \mathrm{Li}+{ }^{23} \mathrm{Na}+{ }^{39} \mathrm{~K}+{ }^{85} \mathrm{Rb}+\right.$ ${ }^{133} \mathrm{Cs}$ ) measured in the studied samples is divided here into low (sum $<1 \%$ ), medium $(1 \%<\mathrm{sum}<2 \%$ ) and high (sum $>2 \%$ ). Samples from Colombia presented a low sum of alkalis, ranging from $0.30 \%$ to $0.73 \%$ (average: $0.46 \%$, median: $0.43 \%$ ), from Russia $0.65 \%$ to $1.04 \%$ (average: $0.80 \%$, median: $0.75 \%$ ), from Brazil $0.75 \%$ to $1.30 \%$ (average: $1.02 \%$, median: $1.05 \%$ ), from Afghanistan $0.49 \%$ to $1.60 \%$ (average: $1.03 \%$, median: $1.16 \%)$ and all the rest of the samples presented a medium to high sum of alkalis $(2.29 \%$ 
for a sample from Zimbabwe). Thus, the emeralds studied from Type IA occurrences can be separated into those with a low to medium sum of alkalis $<1.30 \%$ (from Brazil and Russia) and those with a sum $>1.35 \%$ (all the other emeralds of the same type; i.e., from Ethiopia, Madagascar, Zambia and Zimbabwe).

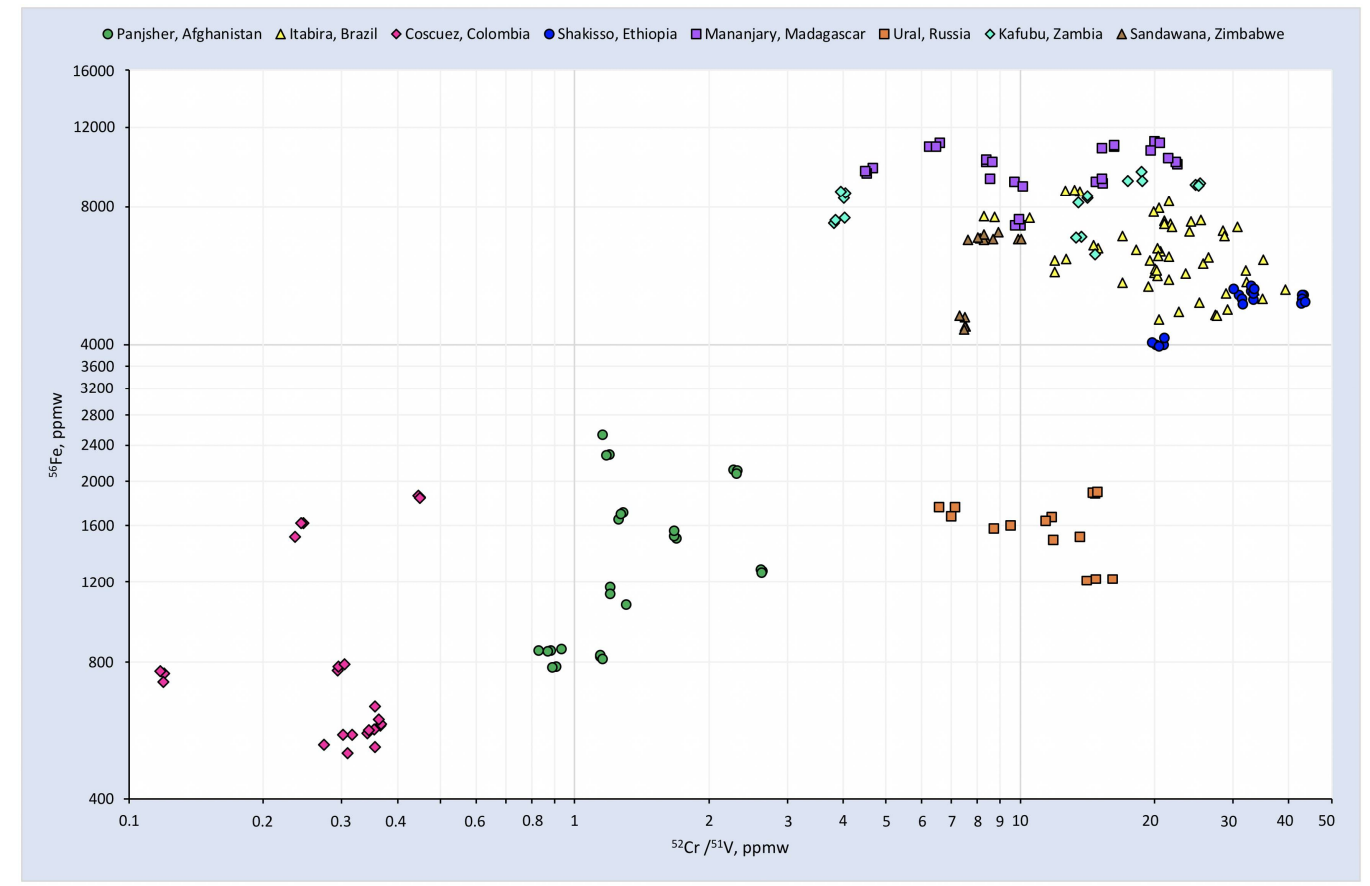

Figure 2. Binary plot of ${ }^{52} \mathrm{Cr} /{ }^{51} \mathrm{~V}$ vs. ${ }^{56} \mathrm{Fe}$.

The alkali metal concentration of emeralds from different localities can vary and their plots are useful for separating them $[14,42,70,81]$. The studied samples can be divided into those with relatively low ${ }^{7} \mathrm{Li}(<200 \mathrm{ppmw})$-Afghanistan, Brazil, Colombia and Madagascar, and those with medium to high ${ }^{7} \mathrm{Li}$ (>250 ppmw)-Ethiopia, Russia, Zambia and Zimbabwe (see Table 3). In parallel, the samples from Colombia did not present a detectable amount of ${ }^{39} \mathrm{~K}$. The samples from Russia contained low amounts of potassium, with some measurements being below quantification limits (BQL). Samples from Madagascar showed the highest concentrations of potassium (up to $3150 \mathrm{ppmw}$, with $1389 \mathrm{ppmw}$ average and 1090 ppmw median values) and the concentrations of emeralds from Afghanistan varied from low (107 ppmw) to high (1540 ppmw). In Figure 3, a ${ }^{7} \mathrm{Li}$ vs. ${ }^{39} \mathrm{~K}$ binary plot of the studied samples is presented. Samples with low lithium $\left({ }^{7} \mathrm{Li}<200 \mathrm{ppmw}\right)$ can be separated from those with medium to high lithium ( $\left.{ }^{7} \mathrm{Li}>250 \mathrm{ppmw}\right)$. Most of the samples from Russia are clustered separately from the other samples with medium to high lithium (Ethiopia, Zambia, Zimbabwe) as they contain relatively little potassium $\left({ }^{39} \mathrm{~K}<105 \mathrm{ppmw}\right)$. The samples from Colombia are not plotted as they do not contain measurable potassium with LA-ICP-MS. In comparison with published data obtained with LA-ICP-MS [70,80,82], the studied samples from Brazil, Ethiopia, Madagascar, Zambia and Zimbabwe presented similar trends. Zambian samples presenting higher potassium and a similar content of lithium, as well as low lithium and high potassium, and samples from Zimbabwe, with relatively low lithium content, have also been presented in previous studies [42,81]. It is also mentioned in a previous publication that some samples from Russia could present higher potassium [55].

In Figure $4 \mathrm{a}^{39} \mathrm{~K}$ vs. ${ }^{23} \mathrm{Na}$ binary plot is presented. As mentioned previously, the samples from Brazil and Madagascar are the only ones studied that belong to the Type IA occurrence type and contain relatively little lithium $\left({ }^{7} \mathrm{Li}<200 \mathrm{ppmw}\right)$. It looks as samples from Madagascar can be further separated from samples from Brazil by using this plot, as the samples from Madagascar contain higher sodium and potassium than the Brazilian samples. Using the same plot, Russian samples can also be further separated from other samples of the Type IA occurrence type by those samples with medium 
to high lithium content (i.e., from Ethiopia, Zambia and Zimbabwe), as they contain low sodium and potassium.

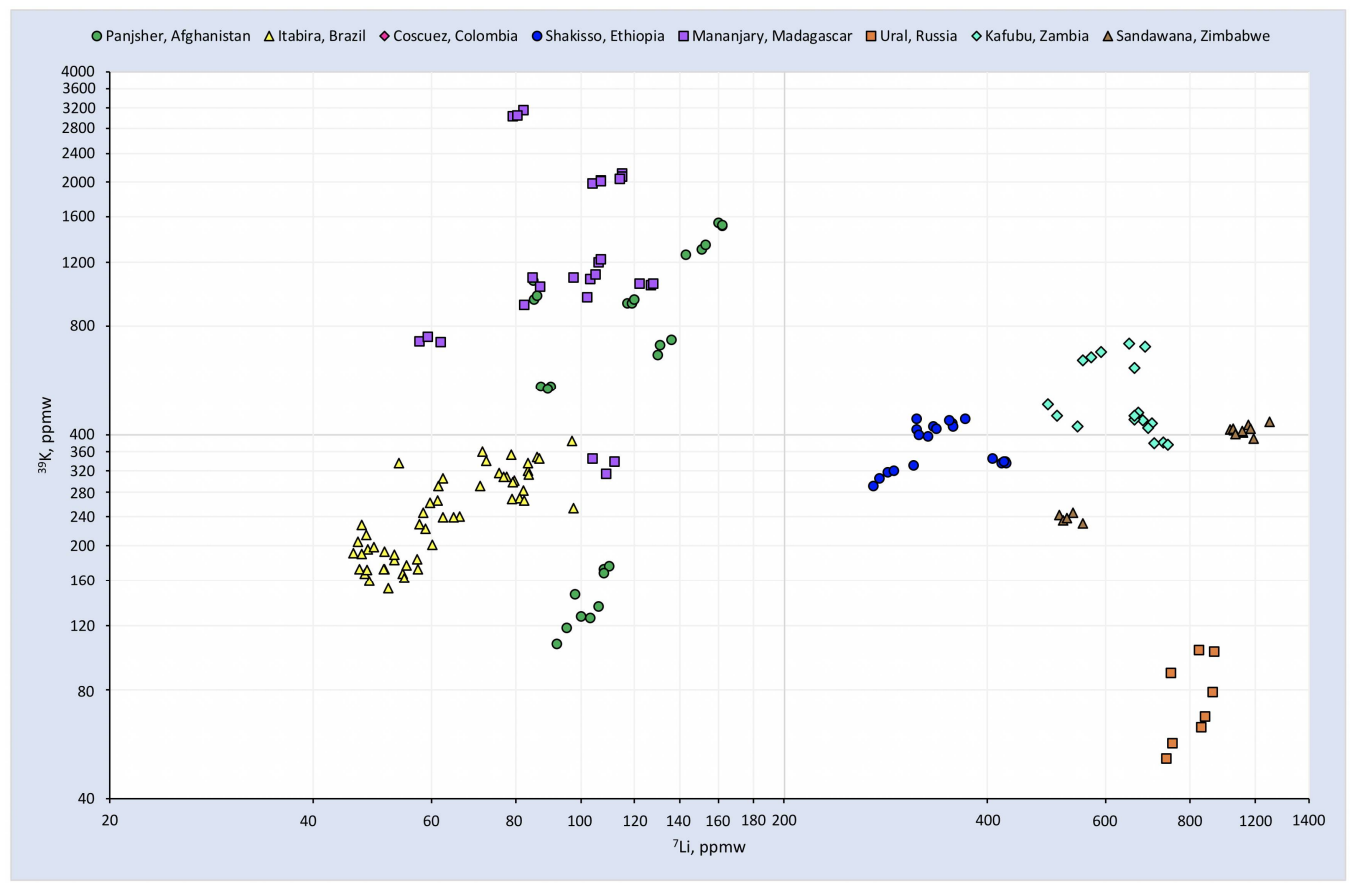

Figure 3. Binary plot of ${ }^{7} \mathrm{Li}$ vs. ${ }^{39} \mathrm{~K}$.

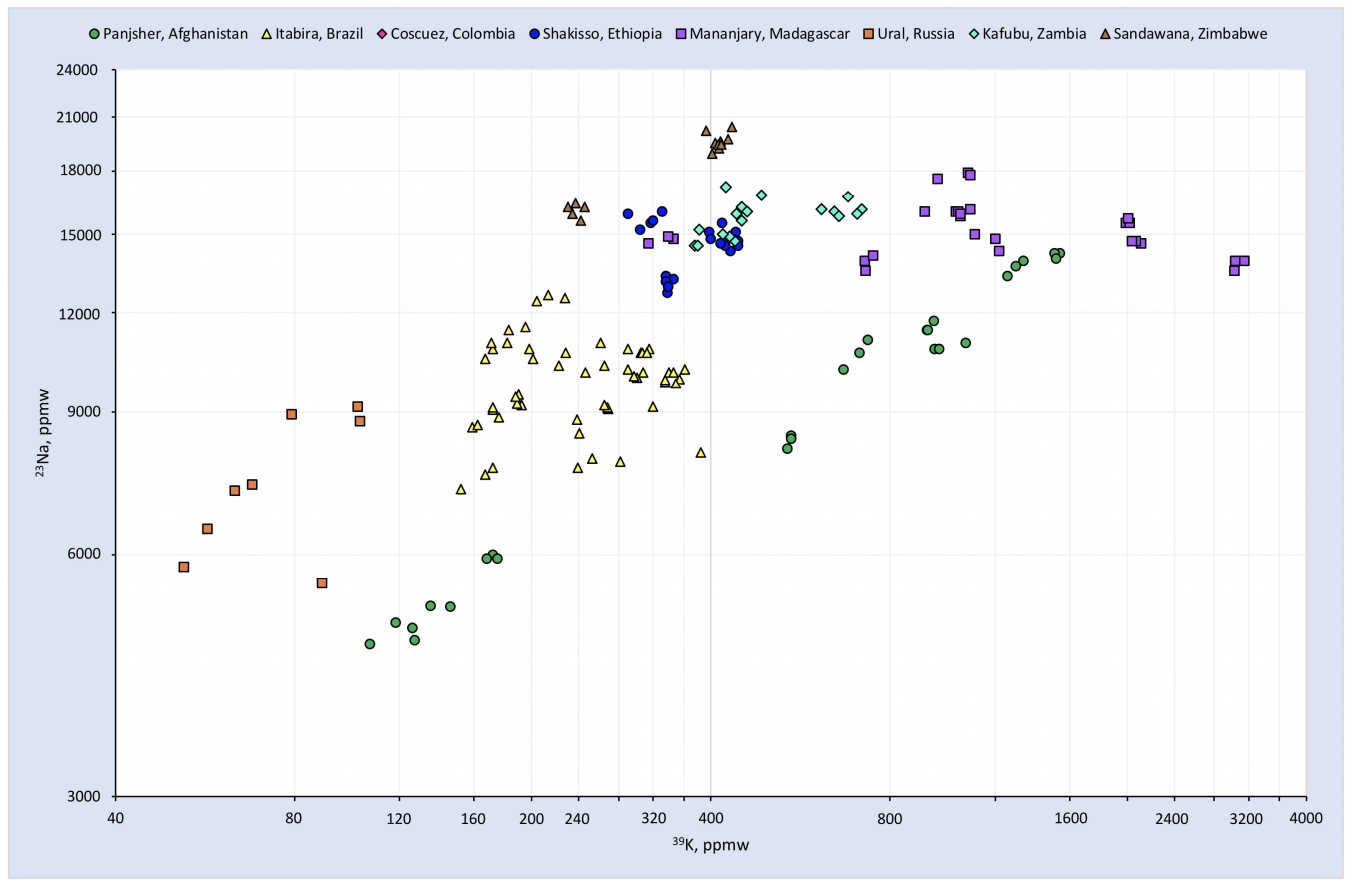

Figure 4. Binary plot of ${ }^{39} \mathrm{~K}$ vs. ${ }^{23} \mathrm{Na}$.

In Figures $5-8,{ }^{85} \mathrm{Rb}$ vs. ${ }^{133} \mathrm{Cs},{ }^{7} \mathrm{Li}$ vs. ${ }^{85} \mathrm{Rb},{ }^{7} \mathrm{Li}$ vs. ${ }^{133} \mathrm{Cs}$ and ${ }^{133} \mathrm{Cs}$ vs. ${ }^{23} \mathrm{Na}$ binary plots are presented, respectively. All measured samples are plotted as they all presented concentrations of lithium, sodium, caesium and rubidium measurable with LA-ICP-MS (see Table 3). Apart for the samples from Brazil and Madagascar, which belong to Type IA occurrences, the samples from Colombia and Afghanistan present low ${ }^{7} \mathrm{Li}$. Samples from Colombia also presented the lowest rubidium $\left({ }^{85} \mathrm{Rb}<1.88 \mathrm{ppmw}\right)$ and caesium $\left({ }^{133} \mathrm{Cs}<12.1 \mathrm{ppmw}\right)$, whereas samples from Zimbabwe presented 
the highest rubidium $\left(167 \mathrm{ppmw}<{ }^{85} \mathrm{Rb}<227 \mathrm{ppmw} ; 264\right.$ ppmw average and 279 ppmw median concentrations). Some of the samples from Madagascar also presented high rubidium ( ${ }^{85} \mathrm{Rb}>100 \mathrm{ppmw}$, up to $317 \mathrm{ppmw}$ ). Samples from Zambia presented the highest caesium content (from 941 to $1410 \mathrm{ppmw}$, 1202 ppmw average and 1215 ppmw median values). According to the literature, some samples from Zambia (Kafubu) could have relatively low lithium [42,70], while some have lower caesium and rubidium [40]. Samples from Colombia are plotted separately in the three plots of Figures 5-7 as they contain the lowest rubidium, caesium and lithium. Samples from Zimbabwe and most samples from Madagascar contain high rubidium and caesium and so they are also plotted separately (see Figure 5). Samples from Madagascar and Zimbabwe can be separated as the former have a low lithium content and the latter have a high content (Figures 6 and 7). Samples from Ethiopia and Zambia are well separated in a ${ }^{7} \mathrm{Li}$ vs. ${ }^{133} \mathrm{Cs}$ binary plot (Figure 7), as samples from Zambia contain the highest caesium; however, a slight overlap was observed between the two in another publication [81]. Emeralds in close connection with highly evolved pegmatites present high lithium and caesium (see Figure 7; emeralds from Russia, Zambia and Zimbabwe) as most of the extremely fractionated rare-element granitic pegmatites of the complex LCT (lithium, caesium, tantalum) association are enriched in lithium and caesium [70,83]. Possible differences in the alkalis of emeralds of Type IA could be linked to the difference between their granites-pegmatites [83-87]. In comparison with published data obtained with LA-ICP-MS [42], the samples from Zambia and Zimbabwe presented similar trends; a few Zambian samples presented higher potassium and a similar content of lithium, and a few others presented lower lithium, lower caesium and higher potassium. The lithium and caesium content of the studied samples from Afghanistan did not vary much; however, potassium, sodium and rubidium exhibited a great variation (see Table 3). In Figure 8, in a ${ }^{133} \mathrm{Cs}$ vs. ${ }^{23} \mathrm{Na}$ binary plot, samples from Colombia, Brazil, Ethiopia, Russia and Zambia shows that individual measurements from each of these localities are clustered closely, whereas those obtained from Afghanistan, Madagascar and Zimbabwe present a wide variation.

${ }^{45} \mathrm{Sc},{ }^{55} \mathrm{Mn},{ }^{59} \mathrm{Co},{ }^{60} \mathrm{Ni},{ }^{66} \mathrm{Zn}$ and ${ }^{69} \mathrm{Ga}$ could also help with the determination of emeralds' origin. ${ }^{59} \mathrm{Co},{ }^{60} \mathrm{Ni}$ and ${ }^{66} \mathrm{Zn}$ were $\mathrm{BQL}$ for all the samples from Afghanistan and Colombia; all studied samples belonging to Type IA occurrence presented ${ }^{59} \mathrm{Co}$ and ${ }^{66} \mathrm{Zn}$ and, some of them, measurable ${ }^{60} \mathrm{Ni}$ with LA-ICP-MS (see Table 3). Nickel could be used to separate Malagasy from Brazilian samples (both with low lithium); it is detectable in the former (average: $28.94 \mathrm{ppmw}$ ) and BQL for the latter. Some samples from Afghanistan as well as most samples of Type IA occurrence presented detectable manganese, and the samples from Zimbabwe presented the highest zinc and manganese contents of the studied samples. Emeralds from Colombia presented the highest gallium content ( 27.5 to $58.5 \mathrm{ppmw}$ ), followed by emeralds from Zimbabwe (24.8 to $33.7 \mathrm{ppmw}$ ), while those from Brazil had the lowest (6.68 to 13.8 ppmw). Nevertheless, Colombian samples with low gallium are cited in the literature $[42,64]$. Scandium is also present in all studied samples, with emeralds from Afghanistan presenting a large variation and the highest content (148 to 2390 ppmw; high scandium in emeralds from Afghanistan was also noted in $[40,42,64])$. Also, Colombian samples presented a variation from relatively low to high content of scandium ( 9.17 to $441 \mathrm{ppmw}$ ), as well as the Malagasy samples (21 to $309 \mathrm{ppmw}$ ). In Figures 9 and $10,{ }^{69} \mathrm{Ga}$ vs. ${ }^{45} \mathrm{Sc}$ and ${ }^{7} \mathrm{Li}$ vs. ${ }^{45} \mathrm{Sc}$ binary plots are presented, respectively. Samples from Colombia and Zimbabwe are separated from the rest in Figure 9 due to their higher gallium content as well as two out of nine of the studied samples due to their high gallium content. In Figure 10, the samples from Ethiopia are plotted separately in between the samples with low lithium and those with high lithium, as they also contain medium scandium concentrations.

In Figure 11, a binary plot of ${ }^{133} \mathrm{Cs}$ vs. ${ }^{23} \mathrm{Na} /{ }^{7} \mathrm{Li}$ ratio is presented; in this, the studied Ethiopian, Russian and Zambian emeralds (all with ${ }^{7} \mathrm{Li}>250 \mathrm{ppmw}$ ) are well separated. The plotted points of Ethiopian samples overlap only with those from one sample from Zimbabwe and the plotted points from Zambia with the analysis of two out of the three studied samples from Zimbabwe. As mentioned above, the samples from Zimbabwe contain high rubidium and could be easily separated from the 
samples from Ethiopia and Zambia (see again Figures 5 and 6). Our results on the Russian emeralds present slightly lower ${ }^{23} \mathrm{Na} /{ }^{7} \mathrm{Li}$ ratios compared to those presented in [19].

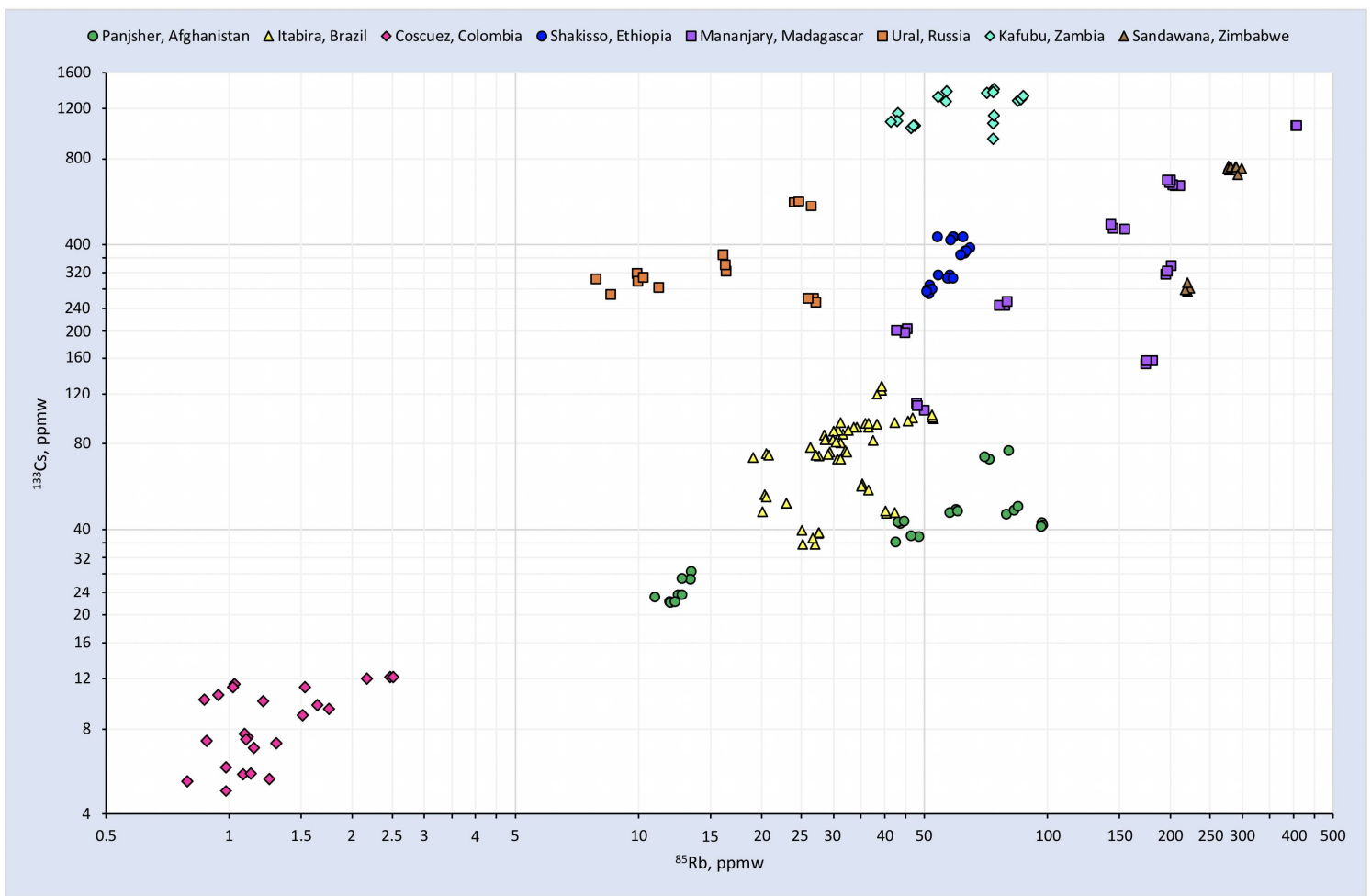

Figure 5. Binary plot of ${ }^{85} \mathrm{Rb}$ vs. ${ }^{133} \mathrm{Cs}$.

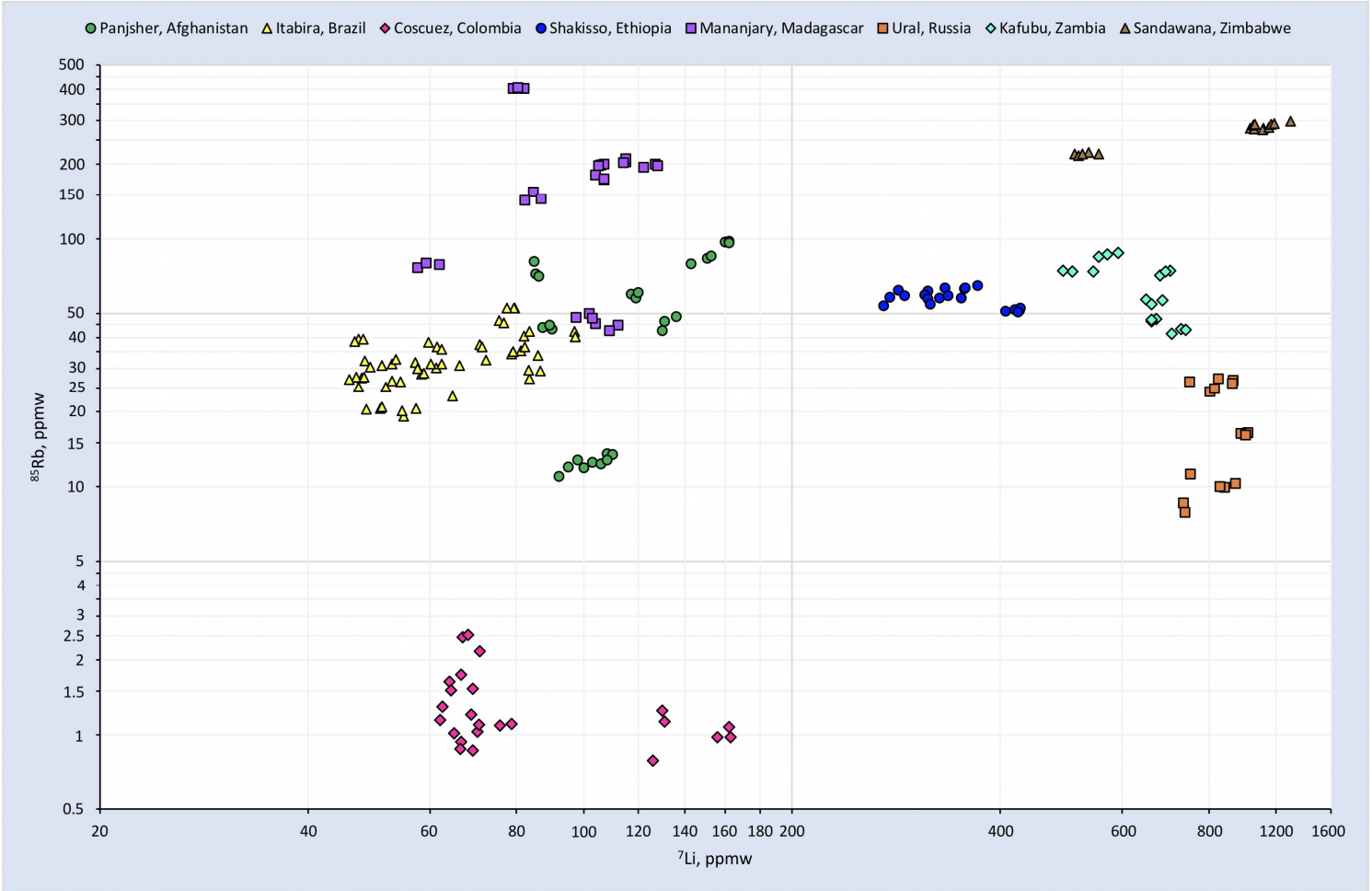

Figure 6. Binary plot of ${ }^{7} \mathrm{Li}$ vs. ${ }^{85} \mathrm{Rb}$. 


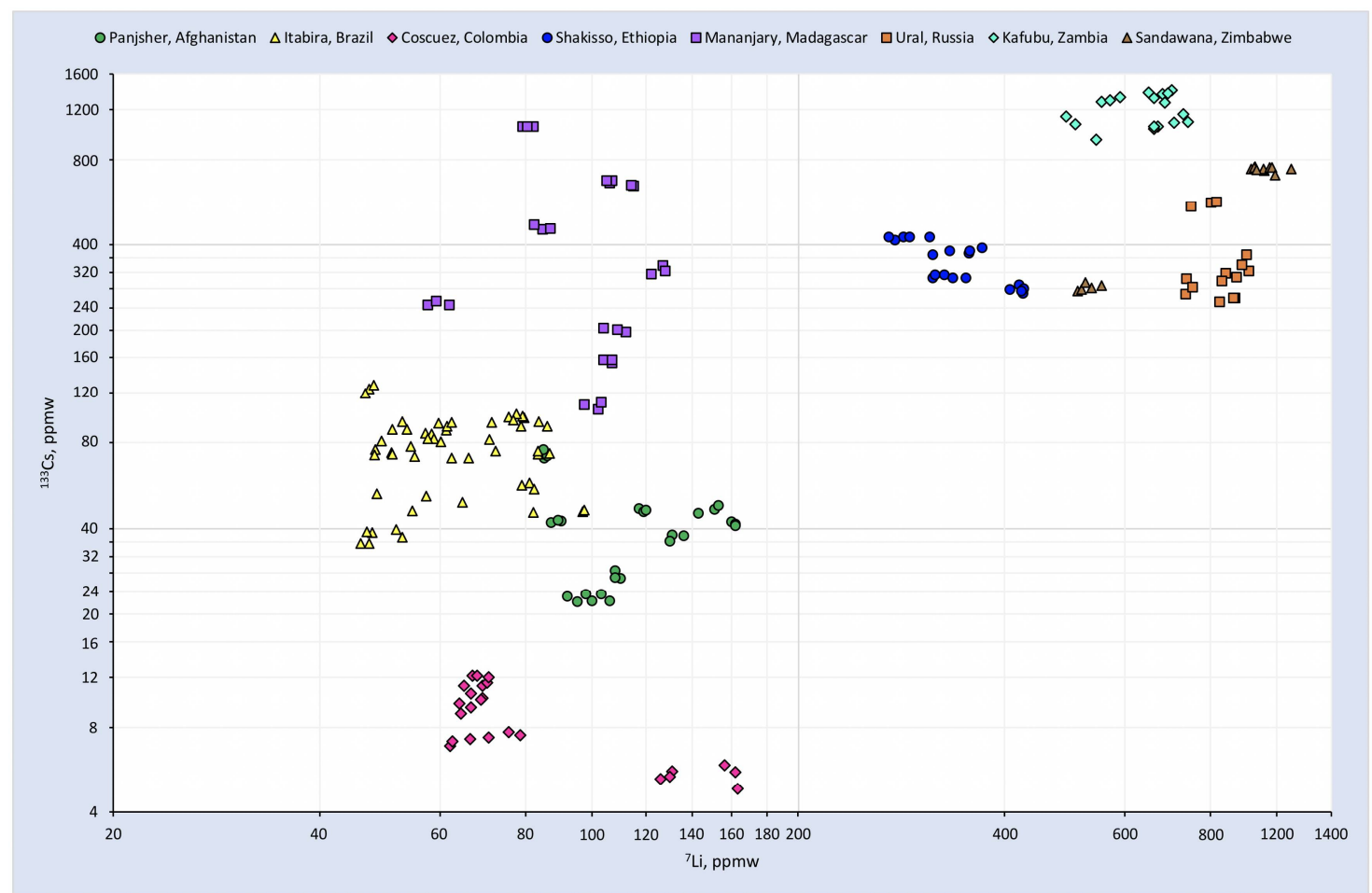

Figure 7. Binary plot of ${ }^{7} \mathrm{Li}$ vs. ${ }^{133} \mathrm{Cs}$.

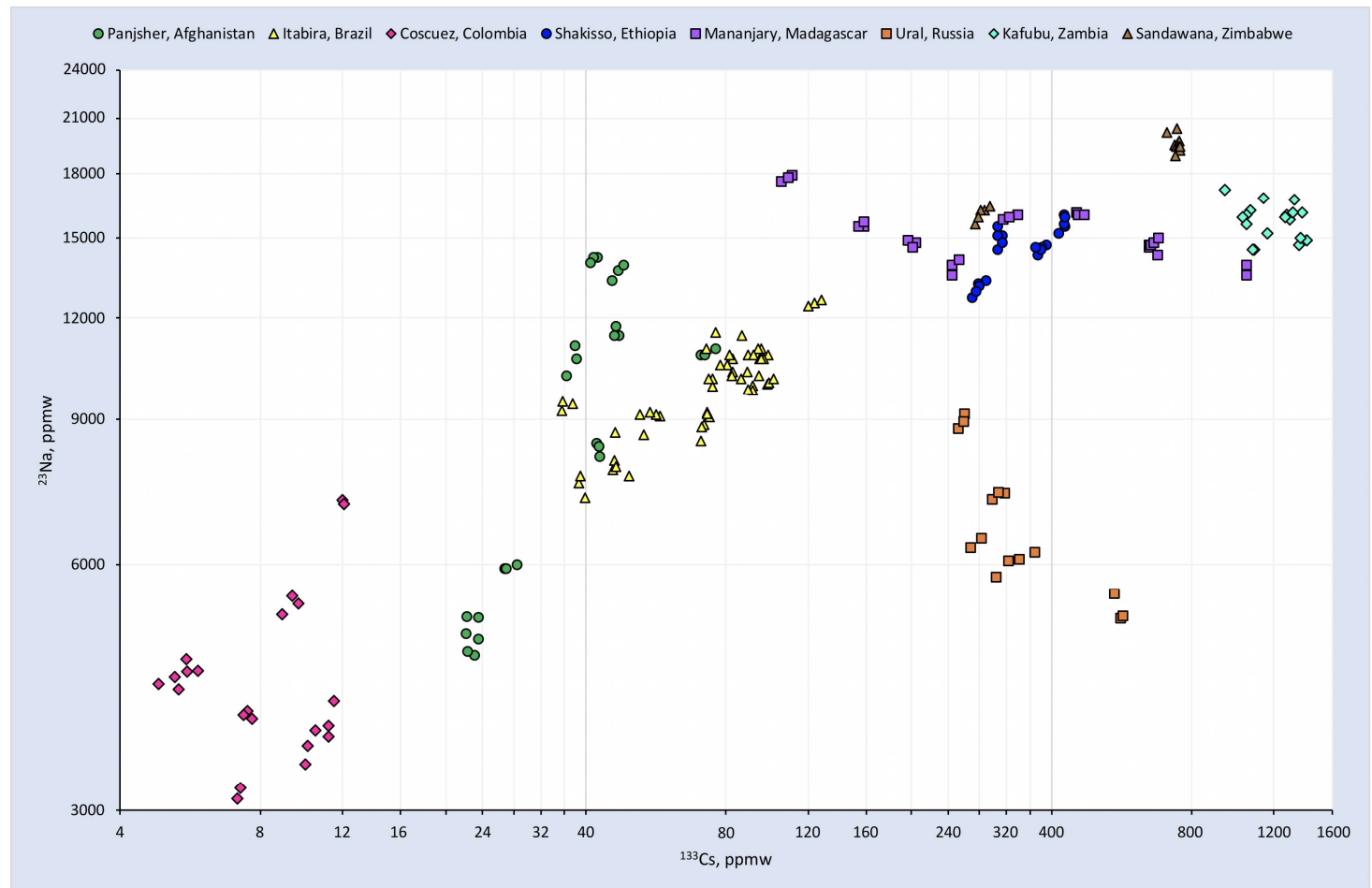

Figure 8. Binary plot of ${ }^{133} \mathrm{Cs}$ vs. ${ }^{23} \mathrm{Na}$. 


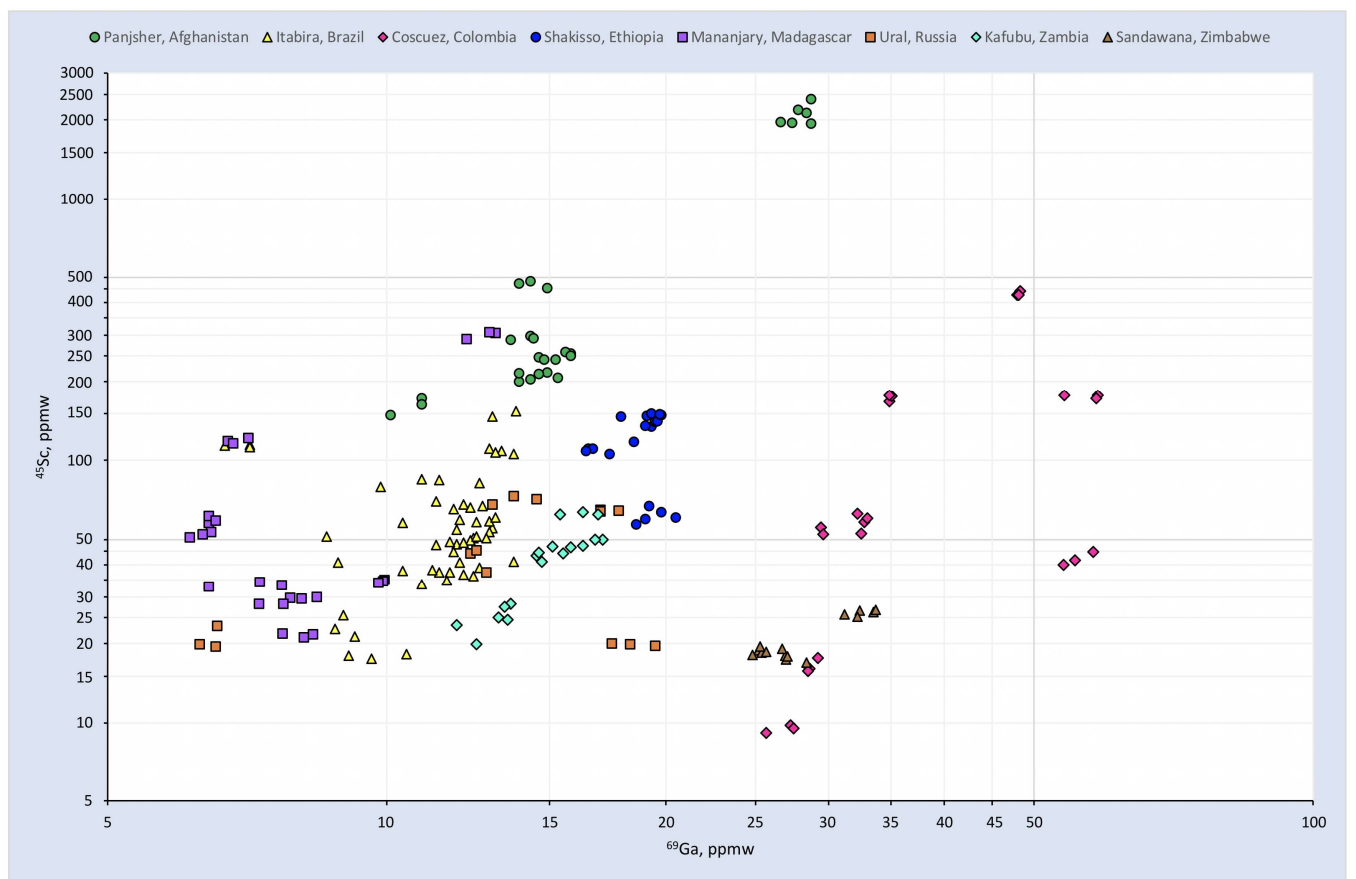

Figure 9. Binary plot of ${ }^{69}$ Ga vs. ${ }^{45}$ Sc.

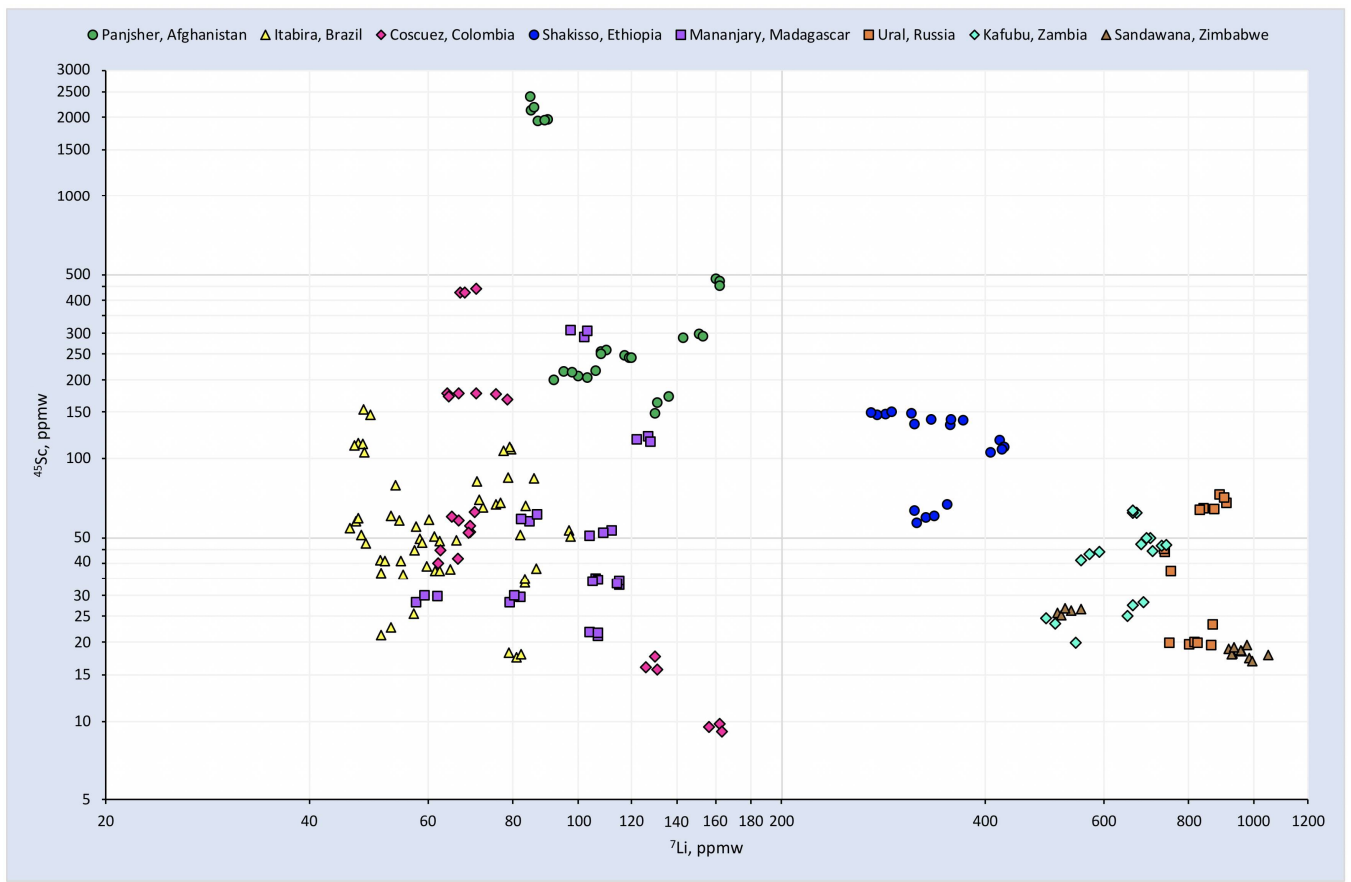

Figure 10. Binary plot of ${ }^{7} \mathrm{Li}$ vs. ${ }^{45} \mathrm{Sc}$.

In Figure 12, a Ga vs. Zn vs. Li triplot is presented, with most samples plotted showing similarity to those presented in [64]; only the samples from Afghanistan differ. Samples belonging to Type II occurrences do not present any measurable zinc with LA-ICP-MS; thus, they are plotted separately from the samples from Type IA occurrences. From the latter, studied samples from Brazil are plotted separately from the studied samples from Madagascar (both present low lithium contents). Some points of the samples from Madagascar overlap with the other samples from Type IA occurrences, but they can be separated as they contain medium to high lithium. 


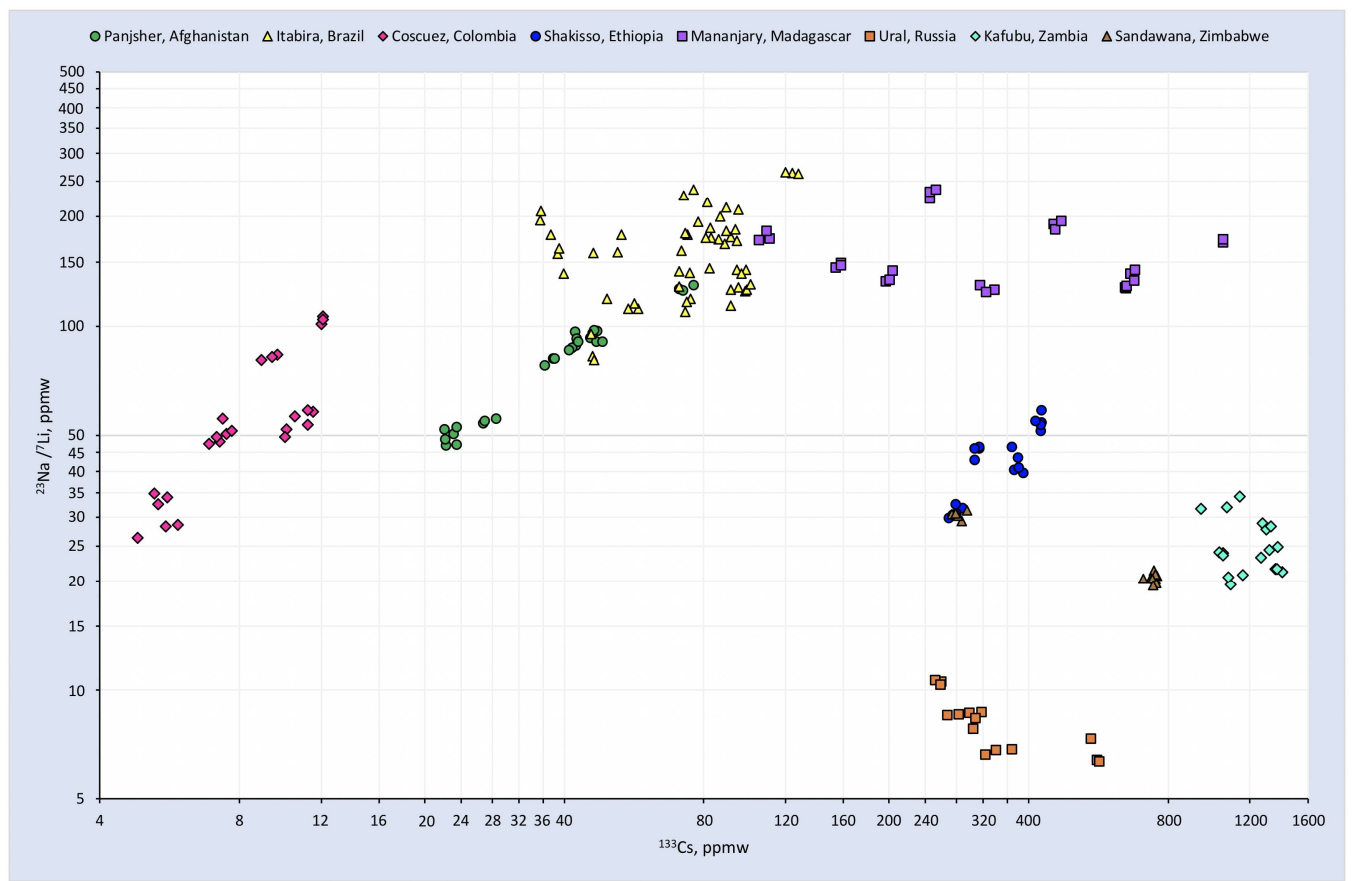

Figure 11. Binary plot of ratios ${ }^{133} \mathrm{Cs}$ vs. ${ }^{23} \mathrm{Na} /{ }^{7} \mathrm{Li}$.

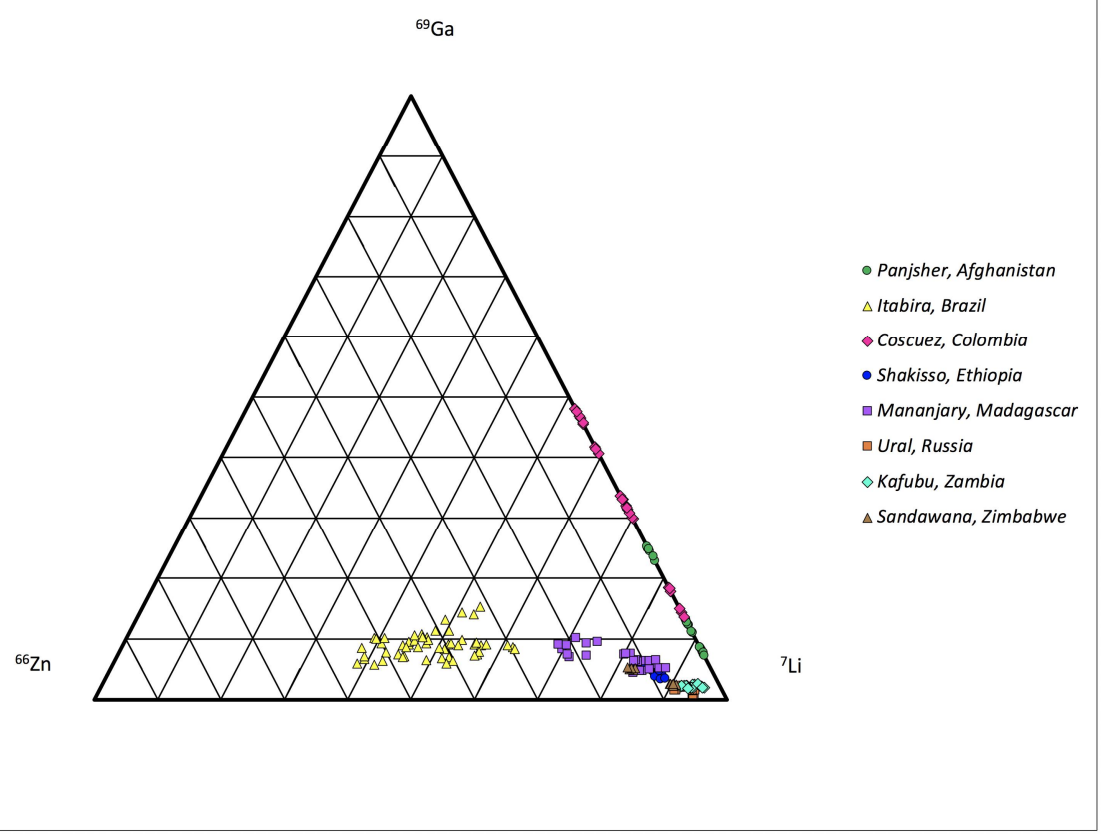

Figure 12. Ternary plot of ${ }^{66} \mathrm{Zn}$ vs. ${ }^{69} \mathrm{Ga}$ vs. ${ }^{7} \mathrm{Li}$.

\subsection{UV-Vis-NIR Spectroscopy}

In Figures 13-15, UV-Vis polarised spectra with a spectral range of 250 to $900 \mathrm{~nm}$ of three green emeralds from Colombia, Afghanistan and Zambia, respectively, are presented. The light blue lines are for the ordinary-ray (o-ray) spectra and the orange lines are for the extraordinary-ray (e-ray) spectra. All emeralds from Colombia (see an example in Figure 13) presented absorptions due to $\mathrm{Cr}^{3+}$ and $\mathrm{V}^{3+}$ in the violet-blue part (around $430 \mathrm{~nm}$ ) and absorption in the orange-red part (around $600 \mathrm{~nm}$ ), with a shoulder at around $395 \mathrm{~nm}$ due to vanadium [34,42,53,62,88-92]. All spectra on the emerald from Afghanistan (Figure 14) show absorptions due to $\mathrm{Cr}^{3+}$ (some of the studied samples also presented the bands due to $\mathrm{V}^{3+}$ ), with relatively low $\mathrm{Fe}^{2+}$-linked absorption at around $830 \mathrm{~nm}$ and very weak 
absorption at around $370 \mathrm{~nm}$ (barely observed along the o-ray) due to $\mathrm{Fe}^{3+}$. All studied emeralds classified as Type IA (i.e., from Brazil, Ethiopia, Madagascar, Russia, Zimbabwe and Zambia) presented absorptions linked to $\mathrm{Cr}^{3+}, \mathrm{Fe}^{3+}$ and $\mathrm{Fe}^{2+}$ (see an example in Figure 15; Table 4). Some samples also presented additional weak bands in the red part of the electromagnetic spectrum, possibly linked to $\mathrm{Fe}^{3+}-\mathrm{Fe}^{2+}$ charge transfer (e.g., from Zambia and Madagascar) [91].

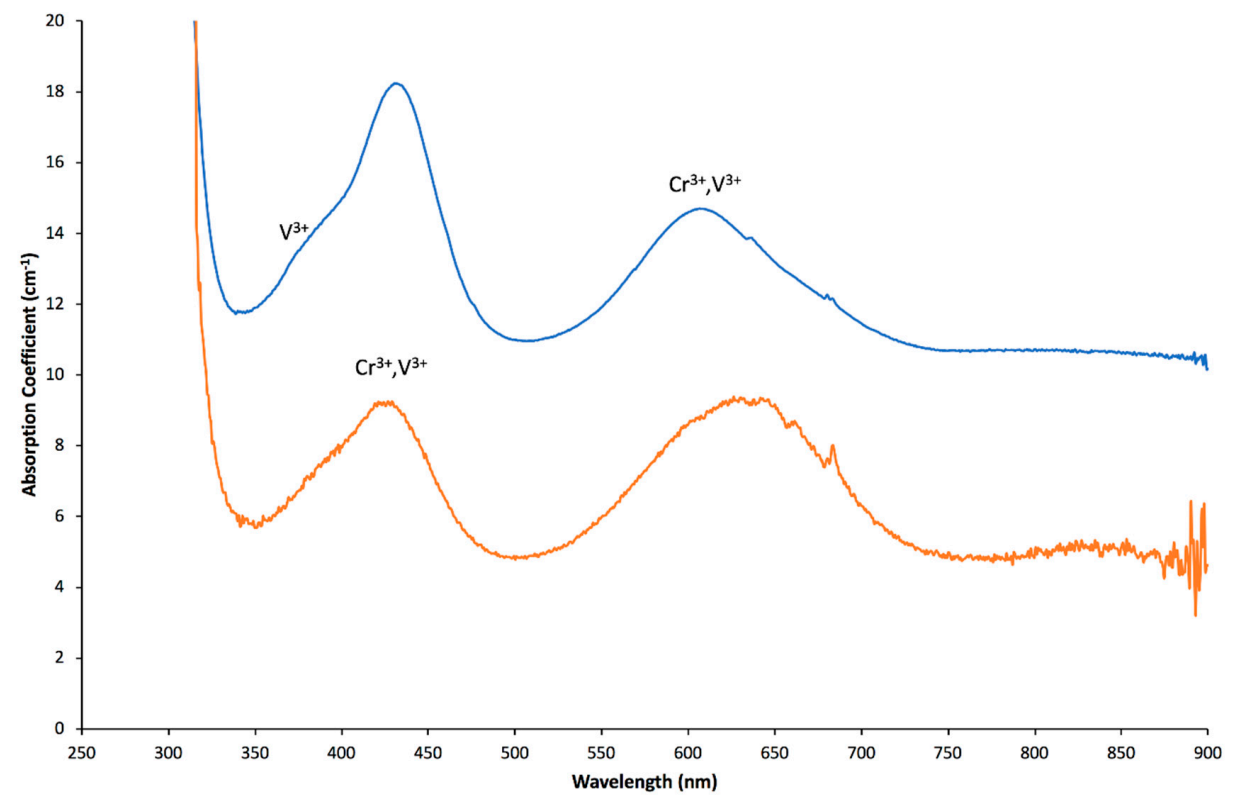

Figure 13. UV-Vis polarized spectra of an emerald from Colombia. The light blue and orange lines are for the o-ray and e-ray spectra, respectively. The upper spectrum has been vertically offset for clarity.

Table 4. UV-Vis absorptions linked with colouring elements of the studied samples.

\begin{tabular}{ccccc}
\hline Locality & $\mathbf{C r}^{3+}$ & $\mathbf{V}^{3+}$ & $\mathbf{F e}^{3+}$ & $\mathbf{F e}^{2+}$ \\
\hline Afghanistan & $\checkmark$ & $\checkmark$ & $(\checkmark)$ & $(\checkmark)$ \\
Brazil & $\checkmark$ & & $\checkmark$ & $\checkmark$ \\
Colombia & $\checkmark$ & $\checkmark$ & & $(\checkmark)$ \\
Ethiopia & $\checkmark$ & & $\checkmark$ & $\checkmark$ \\
Madagascar & $\checkmark$ & & $\checkmark$ & $\checkmark$ \\
Russia & $\checkmark$ & & $\checkmark$ & $\checkmark$ \\
Zambia & $\checkmark$ & & $\checkmark$ & $\checkmark$ \\
Zimbabwe & $\checkmark$ & & $\checkmark$ & $\checkmark$ \\
\hline
\end{tabular}

In Figures 16-18, polarised spectra in the near infrared region (NIR) from 1300 to $1500 \mathrm{~nm}$, of the samples shown in Figures 13-15, are presented. The bands in those figures are linked to water vibrations (overtone and combination). The more pronounced bands observed along the e-ray (orange line) are linked to Type I water (main band at around $1400 \mathrm{~nm}$-around $7142 \mathrm{~cm}^{-1}$ ) and those along the o-ray (light blue line) to Type II water (i.e., water linked with alkalis; main band at $1408 \mathrm{~nm}$-around $7102 \mathrm{~cm}^{-1}$ ) [88,93-95]. Consequently, Type II water bands are more intense in samples with a higher content of alkalis; thus, they are weaker in emeralds from Colombia (Figure 16). The bands are of medium intensity in samples from Brazil, Russia and seven out of nine samples from Afghanistan and one sample out of four from Ethiopia (Figure 17), and intense in all samples from Madagascar, Zambia and Zimbabwe, as well as three out of four from Ethiopia and two out of nine from Afghanistan (Figure 18). 


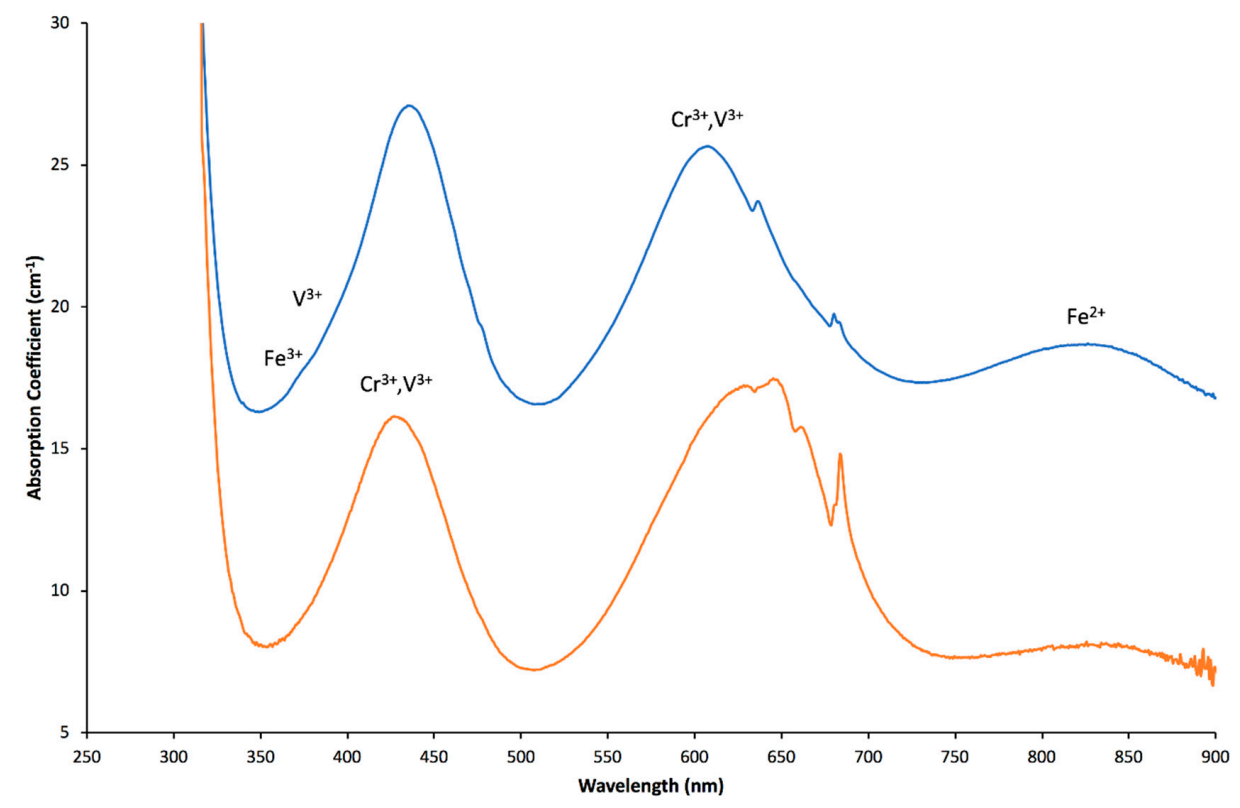

Figure 14. UV-Vis polarized spectra of an emerald from Afghanistan. The light blue and orange lines are for the o-ray and e-ray spectra, respectively. The upper spectrum has been vertically offset for clarity.

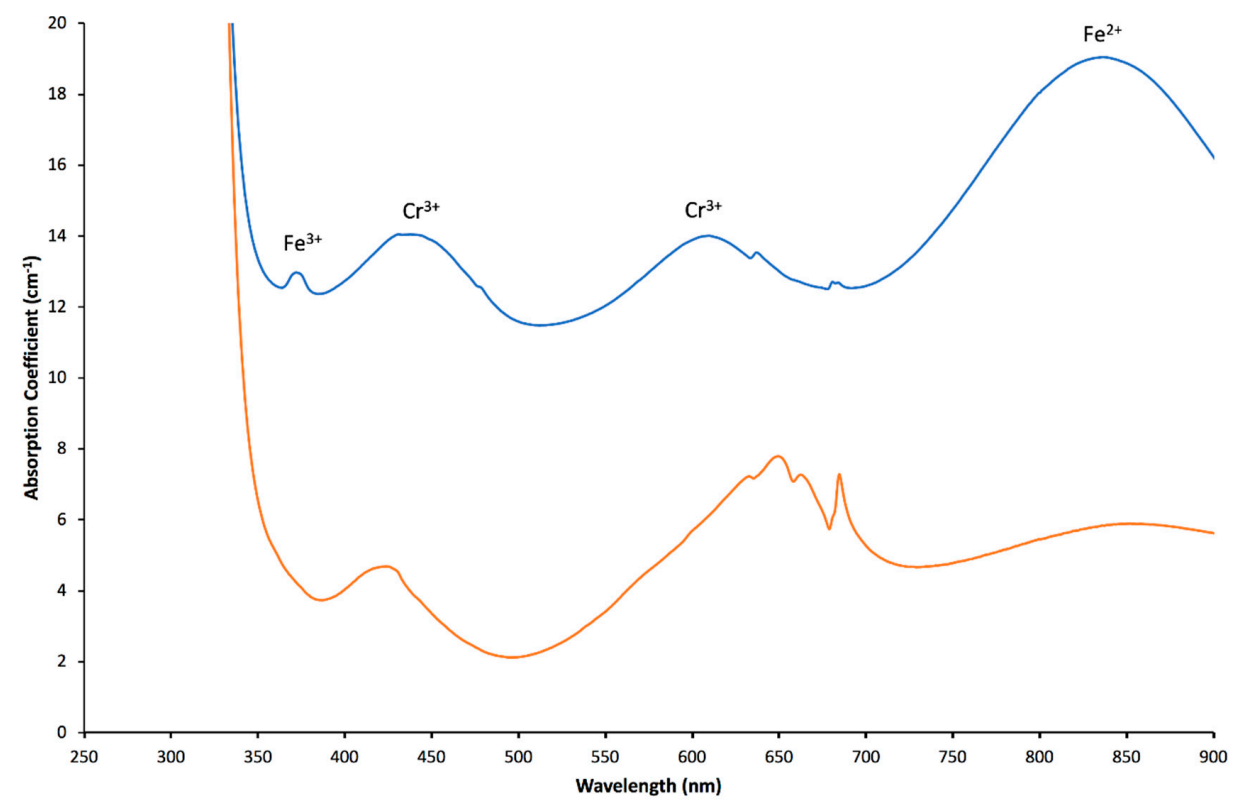

Figure 15. UV-Vis polarized spectra of an emerald from Zambia. The light blue and orange lines are for the o-ray and e-ray spectra, respectively. The upper spectrum has been vertically offset for clarity.

Thus, all emeralds from Type IA occurrences presented relatively important absorptions linked to Type II water; only the samples from Brazil, Russia and one (out of four) from Ethiopia showed medium to weak absorptions of Type II water and pronounced absorptions of Type I water. This is probably due to a lower content of alkalis in these samples compared to the other studied samples from Type IA occurrences. The samples from Colombia and most of the studied samples from Afghanistan (seven out of nine) show similar characteristics to those from Brazil, Russia as well as one from Ethiopia; those from Colombia exhibited the lowest intensity of Type II water bands. Two samples from Afghanistan (belonging to Type II occurrences) present relatively important absorptions linked to Type II water. 


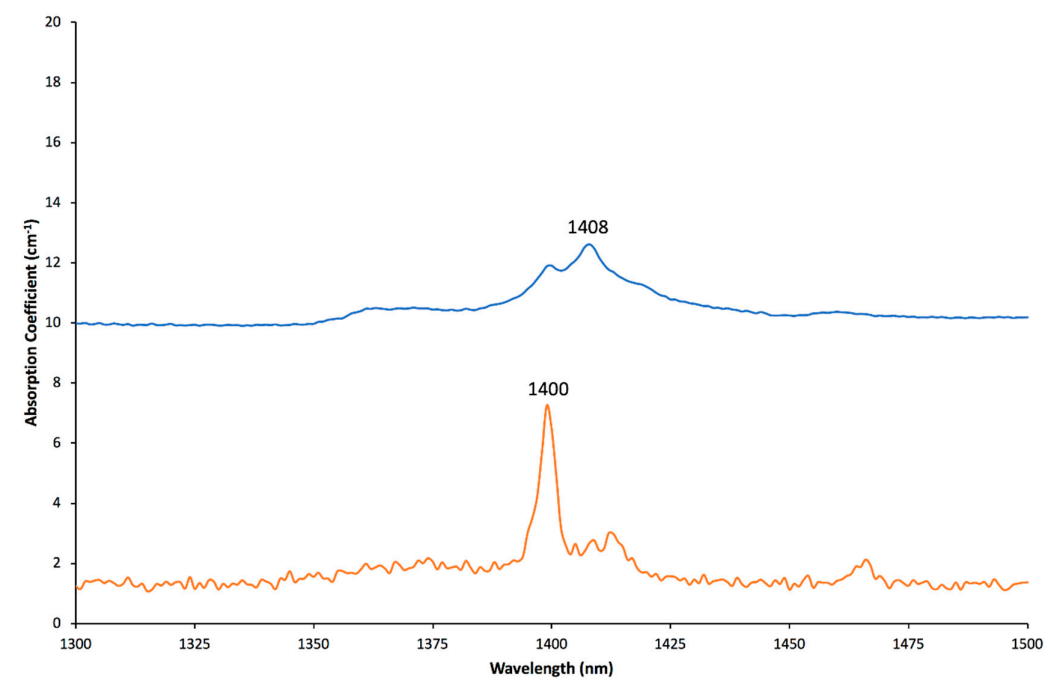

Figure 16. NIR polarized spectra of an emerald from Colombia. The light blue and orange lines are for the o-ray and e-ray spectra, respectively. The upper spectrum has been vertically offset for clarity.

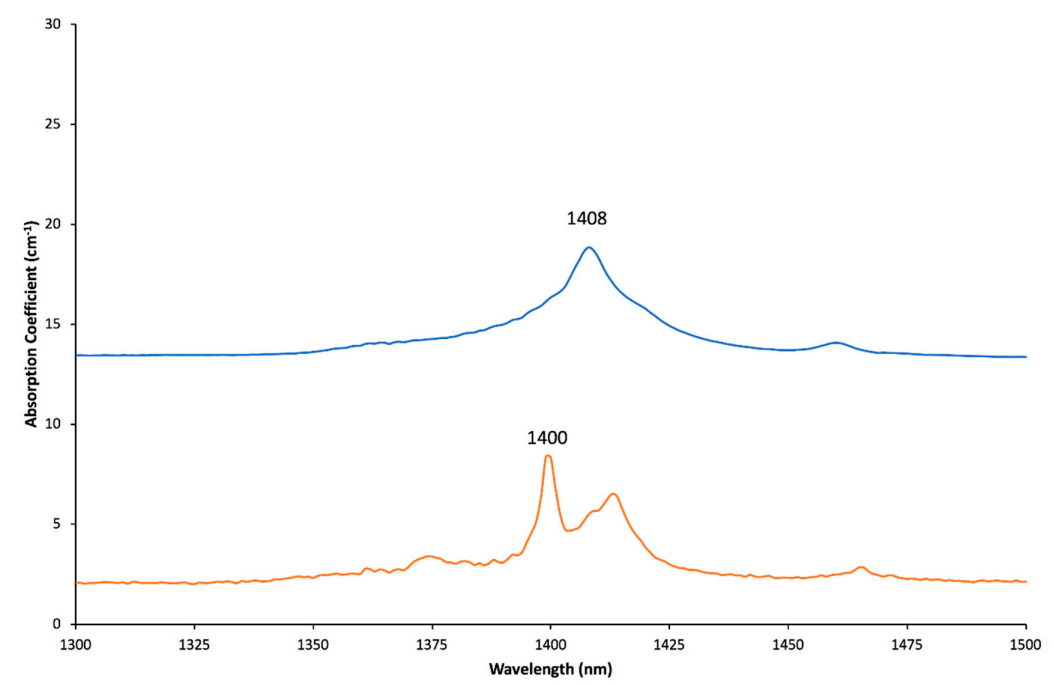

Figure 17. NIR polarized spectra of an emerald from Afghanistan. The light blue and orange lines are for the o-ray and e-ray spectra, respectively. The upper spectrum has been vertically offset for clarity.

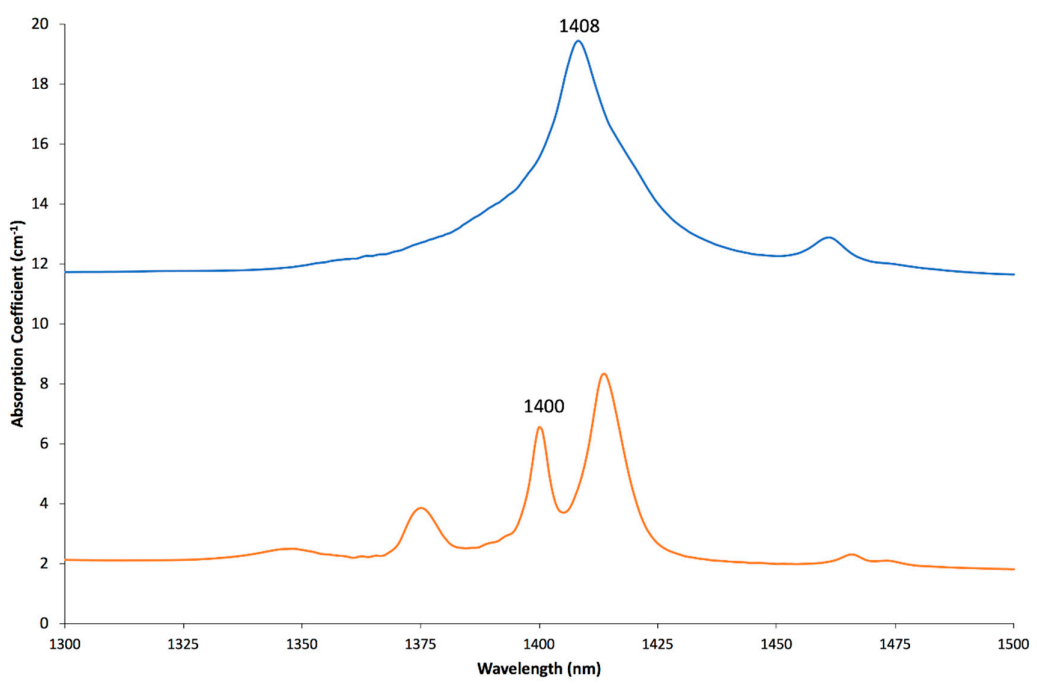

Figure 18. NIR polarized spectra of an emerald from Zambia. The light blue and orange lines are for the o-ray and e-ray spectra, respectively. The upper spectrum has been vertically offset for clarity. 


\subsection{FTIR Spectroscopy}

FTIR spectra were acquired on randomly oriented samples (see an example in Figure 19). At around $3500 \mathrm{~cm}^{-1}$, where the vibrations linked to water molecules' stretching are situated, all samples presented complete absorption due to their thickness. From 4500 to $6000 \mathrm{~cm}^{-1}$, the combination water bands are situated with a series of bands at around $5270 \mathrm{~cm}^{-1}$ that are linked to Type I and Type II water. From $6500 \mathrm{~cm}^{-1}(1538.5 \mathrm{~nm})$ to $7500 \mathrm{~cm}^{-1}(1333.3 \mathrm{~nm})$, overtone and combination water bands are also observed, the same as was observed in the NIR region presented above $[88,93,95]$.

At the region from 2200 to $2850 \mathrm{~cm}^{-1}$ (Figure 20), a series of bands linked to $\mathrm{H}_{2} \mathrm{O}, \mathrm{D}_{2} \mathrm{O}, \mathrm{CO}_{2}$ and chlorine are present $[66,76,95,96]$. More precisely, the bands situated at 2470, 2640, 2670 and $2735 \mathrm{~cm}^{-1}$, which are related to the stretching vibration of deuterated water, are observed in all the spectra of all the studied samples, with differing intensities [97]. An additional band at around $2290 \mathrm{~cm}^{-1}$, is linked to water, is also observed in all studied samples; it is also found in some hydrothermal synthetic emeralds [14,98]. The series of bands from 2300 to $2400 \mathrm{~cm}^{-1}$ (with the main band situated around $2358 \mathrm{~cm}^{-1}$ ) is attributed to $\mathrm{CO}_{2}$ and vibrations linked to the presence of ${ }^{13} \mathrm{C}$ and ${ }^{18} \mathrm{O}$ isotopes $[66,95]$. The band at around $2818 \mathrm{~cm}^{-1}$ was found only in the samples from Colombia and Afghanistan and none of the others, but it was also observed in emeralds from Norway; this band is possibly linked to chlorine $[65,66]$.

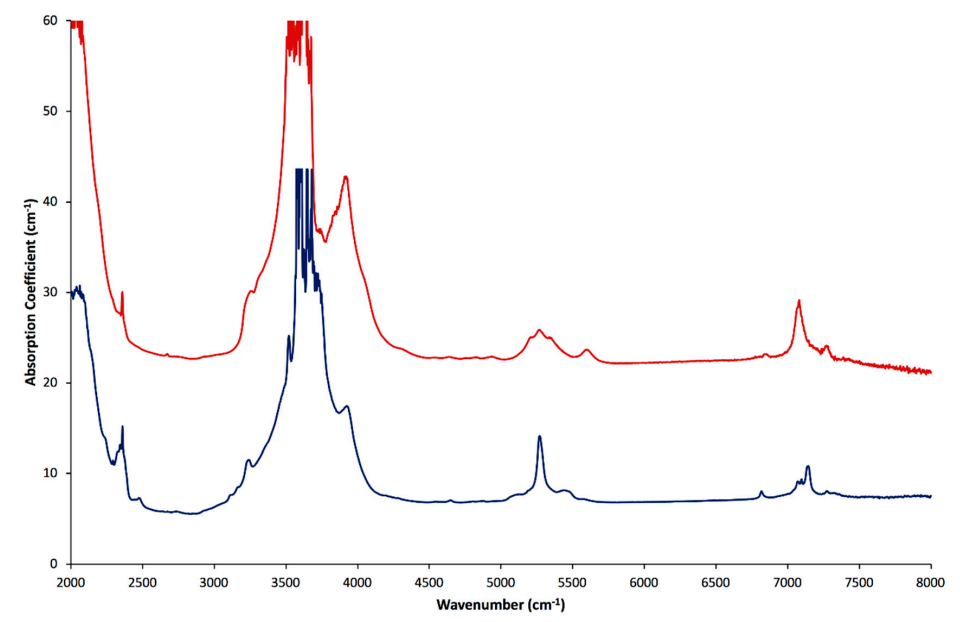

Figure 19. FTIR spectra of an emerald from Colombia (blue spectrum) and from Zimbabwe (red spectrum). The upper spectrum has been vertically offset for clarity.

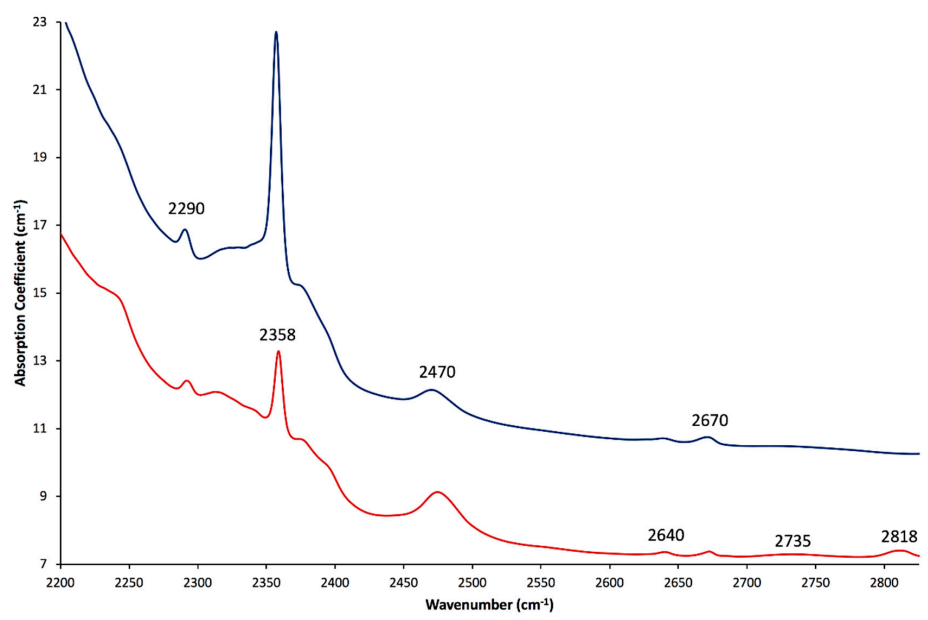

Figure 20. FTIR spectra of an emerald from Colombia (blue spectrum) and from Zimbabwe (red spectrum). The upper spectrum has been vertically offset for clarity. 
Emerald FTIR spectra display strong polarisation phenomena $[95,96]$. For example, deuterated water bands are distinctly more pronounced in spectra acquired along the extraordinary-ray, and $\mathrm{CO}_{2}$ bands are more pronounced along the ordinary-ray $[95,96]$.

\subsection{Raman Spectroscopy}

Raman spectra ranging from 200 to $1300 \mathrm{~cm}^{-1}$ and from 3520 to $3680 \mathrm{~cm}^{-1}$ were acquired on different directions, with the laser beam perpendicular to the c-axis (spectra in black colour) and parallel to the c-axis (spectra in grey colour), without the use of a polariser. The results for an emerald from Colombia are shown in Figures 21 and 22, of an emerald from Ethiopia in Figure 23 and of an emerald from Zambia in Figure 24. Sometimes, it was challenging to acquire a proper spectrum with the $514 \mathrm{~nm}$ laser due to emeralds' chromium luminescence. Bands linked to $\mathrm{Si}_{6} \mathrm{O}_{18}$ ring vibrations are situated below $600 \mathrm{~cm}^{-1}$; the main band at around $686 \mathrm{~cm}^{-1}$ is due to Be-O stretching vibrations, and the main band at around $1070 \mathrm{~cm}^{-1}$ is due to Si-O and/or Be-O stretching $[58,72,95,97,99,100]$. The relative intensities of the Raman bands change following the different orientations; the band at around $686 \mathrm{~cm}^{-1}$ is more intense in spectra acquired with the laser parallel to the c-axis and the band at around $1070 \mathrm{~cm}^{-1}$ is more intense in spectra acquired with the laser perpendicular to the c-axis (Figure 21). The exact position and full width half maximum (FWHM) of the band at $1070 \mathrm{~cm}^{-1}$ was found to be useful for separating natural emeralds from their synthetic counterparts, as well as low-alkali from high-alkali emeralds, where the observed differences are due to silicon substitution with aluminium, beryllium and lithium along with sodium, potassium and caesium for charge compensation [72,73]. In the samples studied, the FWHM of the $1070 \mathrm{~cm}^{-1}$ band (measured from the spectra acquired with the laser perpendicular to the c-axis) in samples with higher alkali content is generally higher (FWHM $<22 \mathrm{~cm}^{-1}$ can be considered for those emeralds of low to medium alkali content), but the position of the band is not shifted towards higher Raman shifts as alkalis increase (see Table 5). It is worth noting that some of the samples studied showed different trends compared with [73]; the samples from Russia and Brazil (Itabira) presented a lower content of alkalis. Additionally, the FWHM depends on the spectral resolution; thus, it can be slightly different when using a different resolution.

The bands at around $3608 \mathrm{~cm}^{-1}$ and $3598 \mathrm{~cm}^{-1}$ are due to Type I water and Type II water, respectively, which also present polarisation phenomena (see again Figures 22-24) $[67,69,99]$. In the present study, the ratios of these Raman peaks' intensities $\left(I_{3608} / I_{3598}\right)$ were greater for the spectra acquired with the laser parallel to the c-axis. The described relative intensities presented in Table 5 are for the spectra acquired with the laser perpendicular to the c-axis.

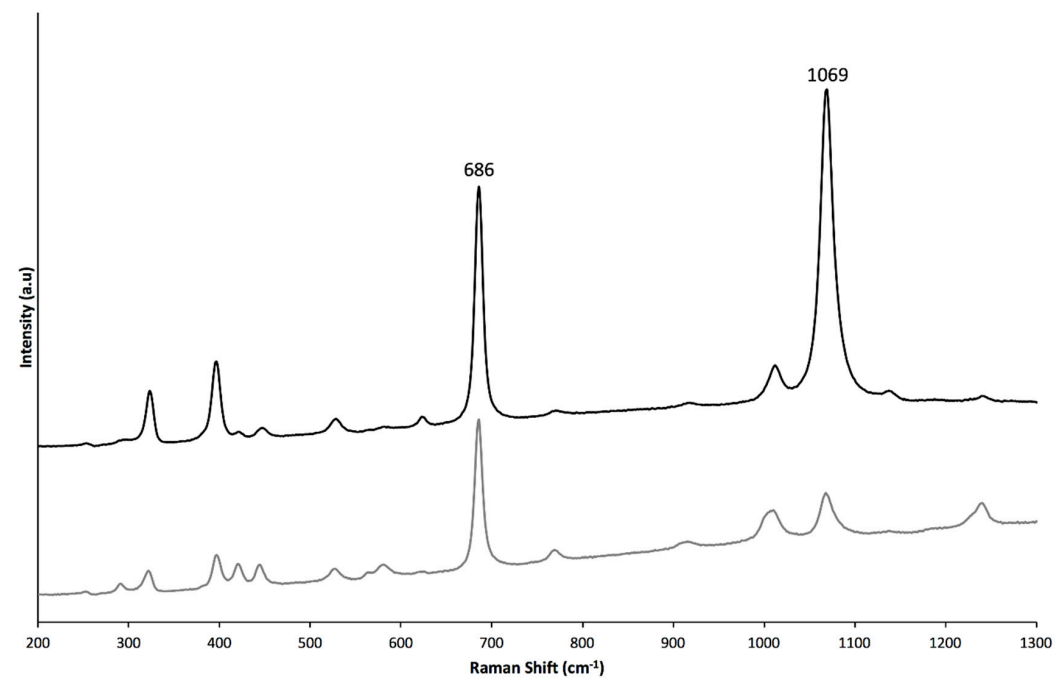

Figure 21. Raman spectra from 200 to $1300 \mathrm{~cm}^{-1}$ of an emerald from Colombia. The black and grey spectra are acquired with the laser beam perpendicular to the c-axis and parallel to the c-axis, respectively. The upper spectrum has been vertically offset for clarity. 


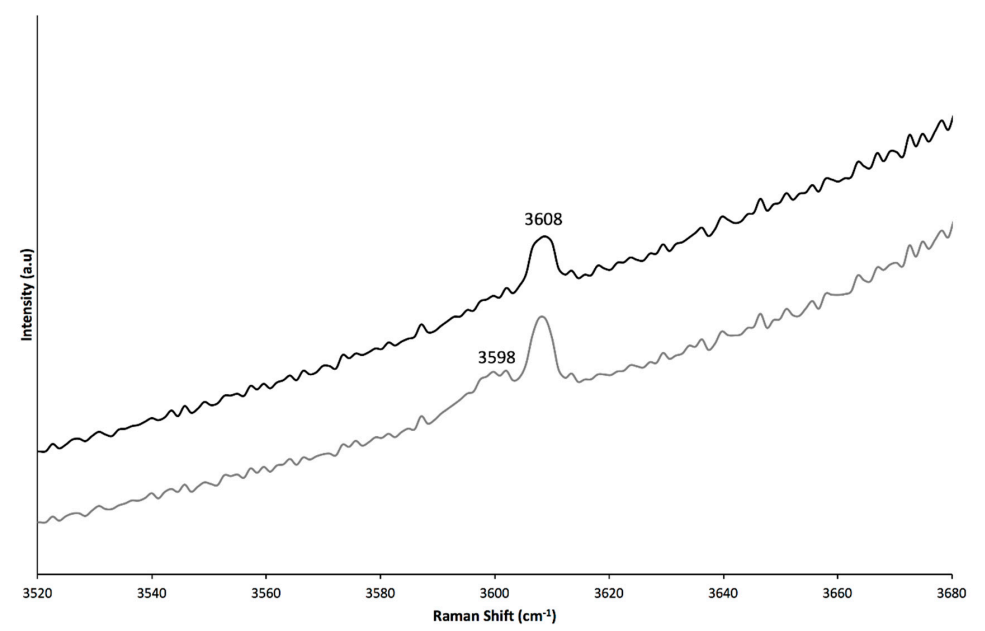

Figure 22. Raman spectra from 3520 to $3680 \mathrm{~cm}^{-1}$ of an emerald from Colombia. The black and grey spectra are acquired with the laser beam perpendicular to the c-axis and parallel to the c-axis, respectively. Note that the upper spectrum is shifted higher for clarity.

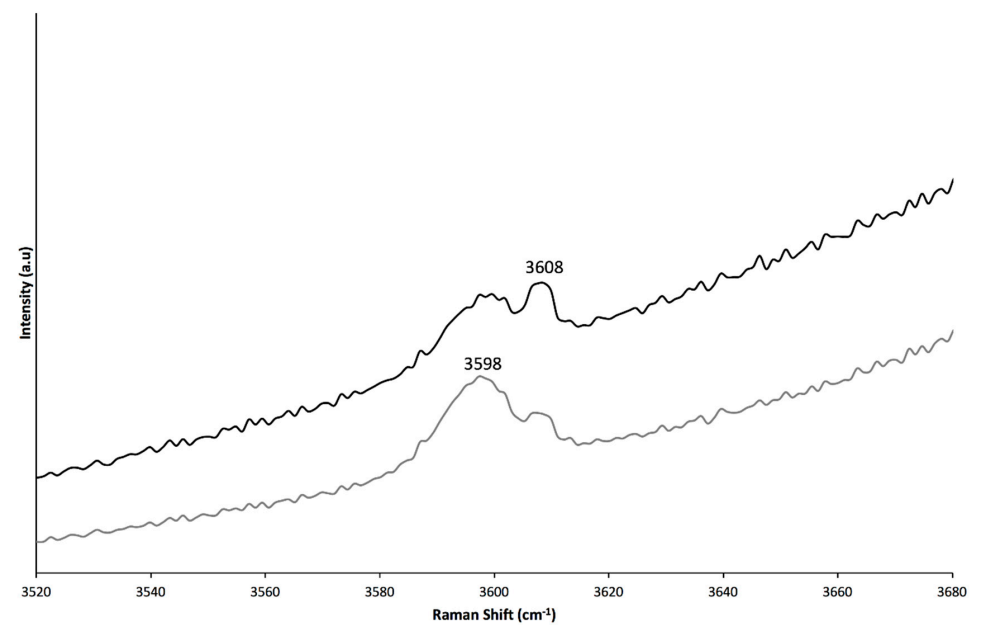

Figure 23. Raman spectra from 3520 to $3680 \mathrm{~cm}^{-1}$ of an emerald from Ethiopia. The black and grey spectra are acquired with the laser beam perpendicular to the c-axis and parallel to the c-axis, respectively. Note that the upper spectrum is shifted higher for clarity.

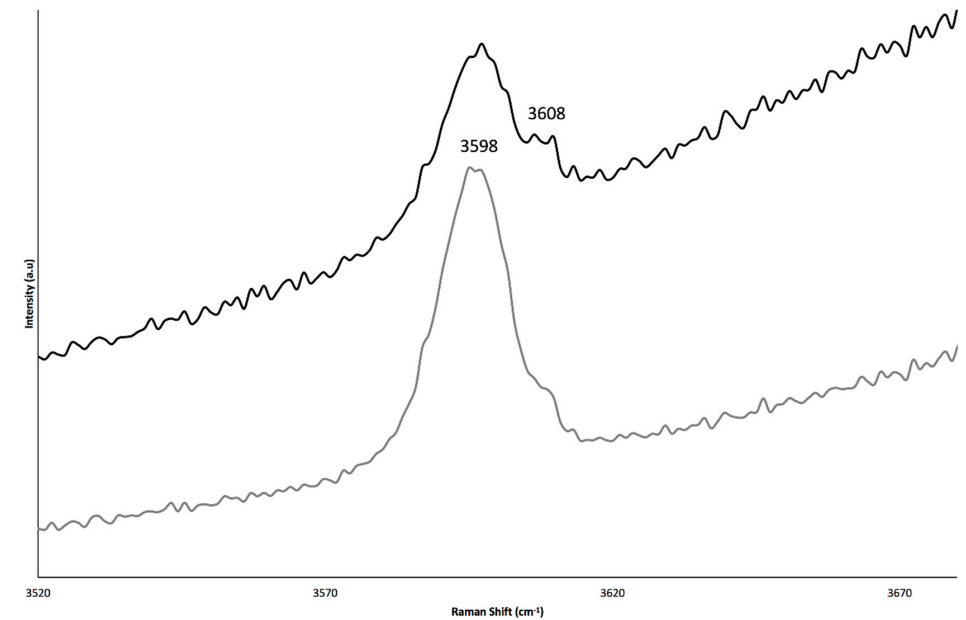

Figure 24. Raman spectra from 3520 to $3680 \mathrm{~cm}^{-1}$ of an emerald from Zambia. The black and grey spectra are acquired with the laser beam perpendicular to the c-axis and parallel to the c-axis, respectively. Note that the upper spectrum is shifted higher for clarity. 
A clear separation between emeralds from Type IA and Type II occurrences cannot be made using Raman spectra (see again Table 5). This is due to the variation of alkali elements' content in the samples from the various geological environments, which might overlap. The Raman peak intensity of $I_{3608}$ is higher than $I_{3598}\left(I_{3608}>I_{3598}\right.$; see Figure 22) for all studied samples from Colombia, some samples from Afghanistan, some from Brazil and from Russia; it is more or less equal ( $I_{3608}=I_{3598}$; see Figure 23) for most samples from Afghanistan, Brazil and Russia, as well as some from Ethiopia, and lower $\left(I_{3608}<I_{3598}\right.$; see Figure 24) for all studied samples from Madagascar, Zambia and Zimbabwe as well as most from Ethiopia (see Table 5).

Table 5. Position and FWHM of the Raman band at around $1070 \mathrm{~cm}^{-1}$, relative intensities of the Raman bands at $3598 \mathrm{~cm}^{-1}$ and $3608 \mathrm{~cm}^{-1}$ and position of the R1 photoluminescence bands for the samples from different localities. All observations were made using spectra acquired with a laser beam perpendicular to the c-axis.

\begin{tabular}{|c|c|c|c|}
\hline Locality & Position \& FWHM & $I_{3608} \& I_{3598}$ Intensities & R1 Position (PL) \\
\hline Afghanistan & $\begin{array}{c}1068.16-1069.92 \\
\text { FWHM }=19.8-24.8\end{array}$ & $\begin{array}{c}I_{3608}=I_{3598} \\
\text { or } I_{3608}>I_{3598}\end{array}$ & $683.7-684.2$ \\
\hline Brazil & $\begin{array}{c}1068.38-1069.87 \\
\text { FWHM }=22.6-23.5\end{array}$ & $\begin{array}{c}I_{3608}=I_{3598} \\
\text { or } I_{3608}>I_{3598}\end{array}$ & $683.9-684$ \\
\hline Colombia & $\begin{array}{c}1069.01-1069.09 \\
\text { FWHM }=19.6-20.7\end{array}$ & $I_{3608}>I_{3598}$ & $683.6-683.8$ \\
\hline Ethiopia & $\begin{array}{c}1069.24-1070.15 \\
F W H M=23.6\end{array}$ & $\begin{array}{c}I_{3608}<I_{3598} \\
\text { or } I_{3608}=I_{3598}\end{array}$ & $684-684.2$ \\
\hline Madagascar & $\begin{array}{c}1069.44-1069.89 \\
F W H M=23.3\end{array}$ & $I_{3608}<I_{3598}$ & $684.2-684.4$ \\
\hline Russia & $\begin{array}{c}1068.81-1069.97 \\
\text { FWHM = } 19.8\end{array}$ & $\begin{array}{c}I_{3608}=I_{3598} \\
\text { or } I_{3608}>I_{3598}\end{array}$ & $683.7-683.8$ \\
\hline Zambia & $\begin{array}{c}1069.11-1069.58 \\
\text { FWHM = } 23.9\end{array}$ & $I_{3608}<I_{3598}$ & 684.3-684.4 \\
\hline Zimbabwe & $\begin{array}{c}1069.91-1071.81 \\
\text { FWHM = 24.6-27.4 }\end{array}$ & $I_{3608}<I_{3598}$ & $684.3-684.4$ \\
\hline
\end{tabular}

\subsection{PL Spectroscopy}

PL spectroscopy of emeralds was suggested as a useful tool to separate natural emeralds from synthetic ones, as well as to aid in emerald origin determination $[58,61,72,74]$. PL bands' intensities and positions vary slightly in different orientations relative to the c-axis [74]. In Figure 25, the photoluminescence spectra with a spectral range from 650 to $850 \mathrm{~nm}$, acquired with the laser beam perpendicular to the c-axis, of emeralds from Colombia (upper spectrum) and Zimbabwe (bottom spectrum) are presented. Both samples presented two sharp bands at around 680 and $684 \mathrm{~nm}$ linked to $\mathrm{Cr}^{3+}$ (also known as $\mathrm{R} 2$ and $\mathrm{R} 1$ lines, respectively), as well as a broad band centred at around $720-740 \mathrm{~nm}$, also linked with chromium [74,101]. It has been suggested that the exact position of the R1 band can give valuable clues on emeralds' natural vs. synthetic nature (no synthetics with $\mathrm{R} 1>683.7 \mathrm{~nm}$ ) as well as on their geologic origin (schist-origin emeralds with R1 < 683.9 nm [74]; see also Figure 26). Table 5 lists the exact position ranges of this band in the spectra of the studied samples. The studied samples show similar trends to those previously presented [74]; however, the emeralds from Brazil and Russia presented R1 bands shifted towards lower wavelengths and at 683.9-684 nm and 683.7-683.8 nm, respectively. Additionally, the R1 band of the studied samples from Afghanistan can vary in position, ranging from 683.6 to $684.2 \mathrm{~nm}$. 


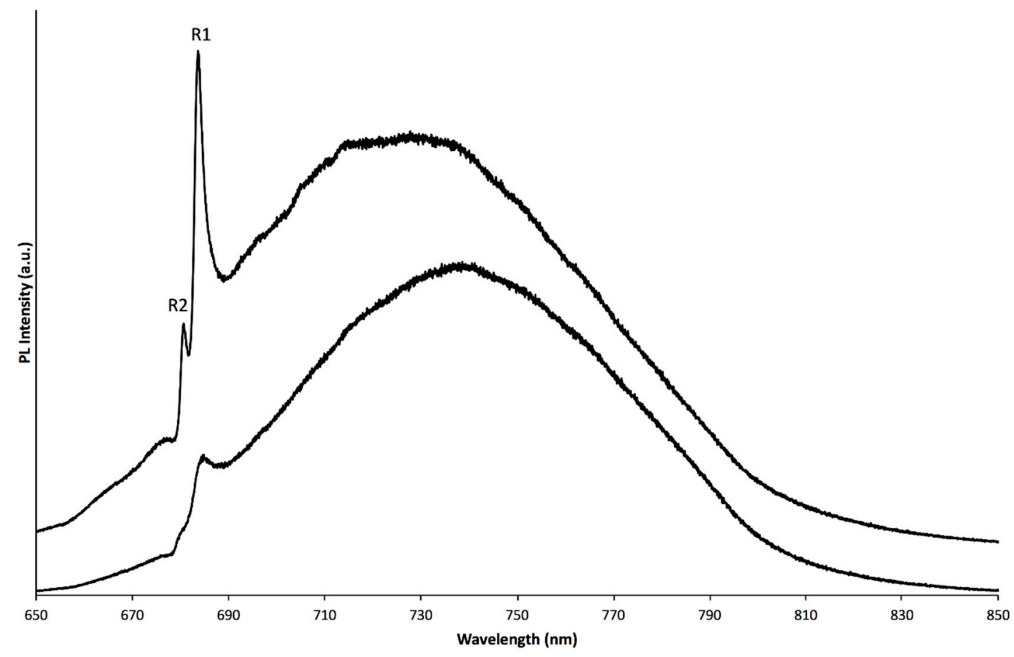

Figure 25. PL spectra from 650 to $850 \mathrm{~nm}$ of an emerald from Colombia (upper spectrum) and an emerald from Zimbabwe (bottom spectrum). Note that the upper spectrum is shifted higher for clarity.

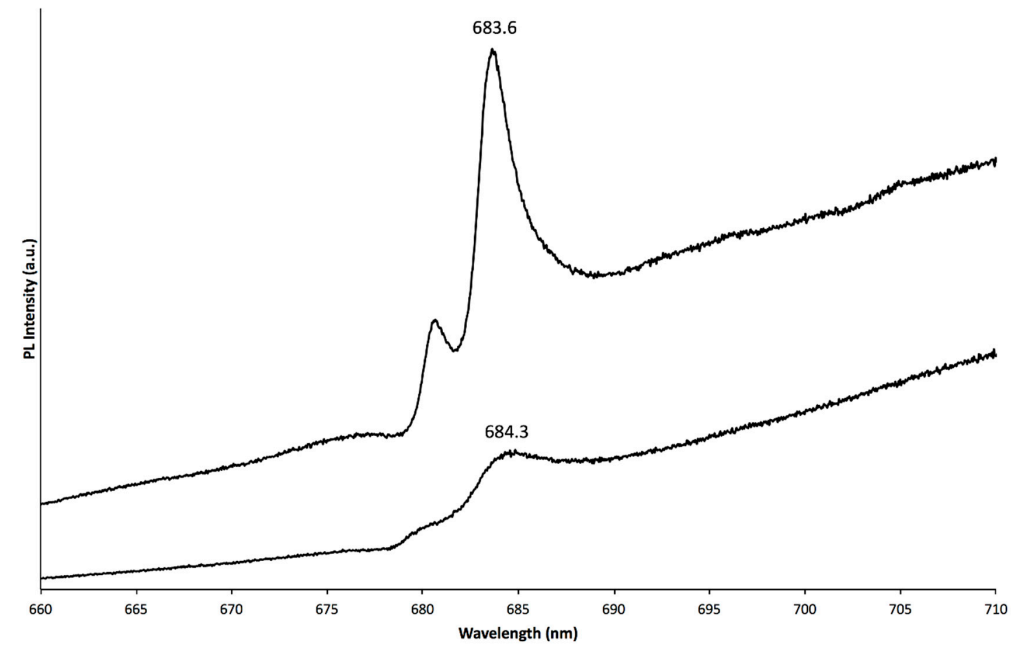

Figure 26. PL spectra from 660 to $710 \mathrm{~nm}$ of an emerald from Colombia (upper spectrum) and an emerald from Zimbabwe (bottom spectrum). Note that the upper spectrum is shifted higher for clarity.

\section{Conclusions}

LA-ICP-MS measurements on emerald samples from the eight most important sources reveal a relatively low lithium content $\left({ }^{7} \mathrm{Li}<200 \mathrm{ppmw}\right)$ for all studied emeralds from Type II occurrences (Afghanistan and Colombia). Additionally, certain emeralds belonging to Type IA occurrences (all samples from Brazil and Madagascar) can also present low lithium content $\left({ }^{7} \mathrm{Li}<200 \mathrm{ppmw}\right.$ ), whereas the emeralds from other Type IA occurrences (Ethiopia, Russia, Zambia and Zimbabwe) present medium to high lithium contents $\left({ }^{7} \mathrm{Li}>250 \mathrm{ppmw}\right)$. Measurements of the concentrations of a combination of alkali elements present in Type IA and Type II occurrences can help with the identification of emeralds from different mining areas. Scandium, manganese, cobalt, nickel, zinc and gallium can further aid with the separation. Origin determination cannot be performed by only studying one element or a single binary plot; it requires a combination of several.

UV-Vis spectra are useful in the separation of Type II emeralds from Type IA emeralds as the former contain iron-related bands of low intensity and the latter are of high intensity. Other spectroscopic data (FTIR, Raman and photoluminescence spectroscopy) on emeralds can further help to separate emeralds with low alkali element contents from those with high alkali element contents. However, there is an overlap between samples from different geological environments; separation using solely these methods should be undertaken with caution. 
Apart from the microscopic characteristics, it seems that using the combination of spectroscopic and chemical characteristics (on green zones) presented in this work, a gem-quality emerald of "unknown" location and of relatively large size $(>1 \mathrm{ct})$, similar to client stones submitted to gemmological laboratories, can be identified. First sorting could be done by using UV-Vis spectroscopy and the intensity of iron-related bands, as emeralds from Type IA occurrences (Brazil, Ethiopia, Madagascar, Russia, Zambia and Zimbabwe) contain intense iron-related bands and in emeralds from Type II occurrences (Afghanistan and Colombia) iron-related bands are absent or of low intensity. Emeralds from Type IA occurrences can be separated into those with low lithium $(<200$ ppmw for emeralds from Brazil and Madagascar) and those with medium to high lithium ( $>250 \mathrm{ppmw}$ for emeralds from Ethiopia, Russia, Zambia and Zimbabwe). Low-lithium emeralds from Brazil contain less sodium, less potassium and no (BQL) nickel as well as more zinc compared to those from Madagascar, so plots combining these elements could help to separate these two. Medium- to high-lithium emeralds from Russia contain less sodium and potassium and rubidium than those from Ethiopia, Zambia and Zimbabwe. Samples from Zimbabwe present higher rubidium, gallium and manganese compared to those from Ethiopia and Zambia. Samples from Zambia contain more caesium and lithium and less scandium than the samples from Ethiopia, so they can be separated using plots combining these elements as well as a binary plot of the ${ }^{133} \mathrm{Cs}$ vs. ${ }^{23} \mathrm{Na} /{ }^{7} \mathrm{Li}$ ratio. Samples from Type II occurrences from Afghanistan and Colombia can be separated as the former contain higher concentrations of potassium, rubidium and caesium than the latter, and the scandium and gallium ratios differ as well.

The abovementioned scheme should be confirmed after studying a larger sample from these areas and taking into account the microscopic features of the samples. Studies on a larger number of gem-quality samples of green to dark green colour from various mining areas in the same region, along with a detailed study of their host rocks (especially of Type IA emeralds), should be performed in order to better understand the link between the trace elements and their geology and to better predict possible variation in the trace elements of emeralds in the same mining region. Statistical analyses (e.g., discriminant analysis) of the chemical data should be performed, as this might provide an additional tool for emeralds' geographic origin determination. Samples from less productive mining areas that have supplied gem-quality emeralds in the past, and might produce again in the future, should be also studied (e.g., Swat Valley, Pakistan; Mushakashi, Zambia; Bahia, Brazil). Additional measurements with a microprobe might help us to better understand the crystallochemistry of the samples. Standards for LA-ICP-MS made of doped emeralds with various elements might decrease any matrix effect and, in parallel, help with the measurement of trace elements with greater accuracy. Additionally, LA-ICP-MS with improved detection limit or analysis with secondary ion mass spectrometry (SIMS) may help further.

Polarised FTIR spectra on well-oriented samples should also be acquired in order to look for potential differences between samples from different mines. Polarized Raman spectra should also be collected in order to have a more accurate comparison between the vibrational data of different emeralds.

Supplementary Materials: The following are available online at http://www.mdpi.com/2075-163X/9/9/561/s1, Table S1: LA-ICP-MS analysis in ppmw of the studied emerald samples from Panjsher, Afghanistan; Table S2: LA-ICP-MS analysis in ppmw of the studied emerald samples from Itabira, Brazil; Table S3: LA-ICP-MS analysis in ppmw of the studied emerald samples from Coscuez, Colombia; Table S4: LA-ICP-MS analysis in ppmw of the studied emerald samples from Shakisso, Ethiopia; Table S5: LA-ICP-MS analysis in ppmw of the studied emerald samples from Mananjary, Madagascar; Table S6: LA-ICP-MS analysis in ppmw of the studied emerald samples from Ural, Russia; Table S7: LA-ICP-MS analysis in ppmw of the studied emerald samples from Kafubu, Zambia; Table S8: LA-ICP-MS analysis in ppmw of the studied emerald samples from Sandawana, Zimbabwe.

Author Contributions: S.K. formulated the paper, designed the experiments, participated in the data interpretation and wrote the manuscript. B.A.-S and F.M. prepared the experiments, did part of the LA-ICP-MS analysis, performed a data reduction, edited the manuscript and drew the figures and tables. S.S. designed, supervised and evaluated the LA-ICP-MS analysis. A.A.-A. selected the samples, designed the experiments and edited the manuscript.

Funding: This research received no external funding. 
Acknowledgments: The authors wish to thank Dietmar Schwarz (ICA Gem Lab, Bangkok, Thailand) for the samples from Brazil and Russia, Christian Dunaigre (C. Dunaigre Consulting GmbH, Le Mont-Sur-Lausanne, Switzerland) for the samples from Brazil, Hanco Zwaan (Naturalis Biodiversity Center, Leiden, Netherlands) for the samples from Zimbabwe, and Vincent Pardieu (VP Consulting, Manama, Bahrain) for collecting the samples for DANAT directly from the mining areas (Madagascar, Zambia, Afghanistan and Colombia) or from trusted sources (Ethiopia).

Conflicts of Interest: The authors declare no conflict of interest.

\section{References}

1. Fritsch, E.; Rossman, G. An update on color in gems Part 3: Colors caused by band gaps and physical phenomena. Gems Gemol. 1988, 24, 81-103. [CrossRef]

2. Johnson, M.L.; Elen, S.; Muhlmeister, S. On the identification of various emerald filling substances. Gems Gemol. 1999, 35, 82-107. [CrossRef]

3. Kiefert, L.; Hänni, H.A.; Chalain, J.-P.; Weber, W. Identification of filler substances in emeralds by infrared and Raman spectroscopy. J. Gemmol. 1999, 26, 501-520. [CrossRef]

4. McClure, S.F.; Moses, T.M.; Tannous, M.; Koivula, J. Classifying emerald clarity at the GIA gem trade laboratory. Gems Gemol. 1999, 35, 176-185. [CrossRef]

5. Information Sheet \#5 Standardised Gemmological Report Wording. Available online: http://www.lmhcgemology.org/pdfs/IS5_20121209.pdf (accessed on 30 July 2019).

6. Hänni, H.A. Origin determination for gemstones: Possibilities, restrictions and reliability. J. Gemmol. 1994, 24, 139-148. [CrossRef]

7. Dereppe, J.M.; Moreaux, C.; Chauvaux, B.; Schwarz, D. Classification of emeralds by artificial neural networks. J. Gemmol. 2000, 27, 93-105. [CrossRef]

8. Schwarz, D.; Giuliani, G.; Grundmann, G.; Glas, M. The origin of emerald-A controversial topic. Extralapis Engl. 2002, 2, 18-21.

9. Gübelin Gem Lab. The roots of origin determination. Jewel. News Asia 2006, 263, 66-71.

10. Gübelin Gem Lab. The limitation of origin determination. Jewel. News Asia 2006, 264, 56-62.

11. Gübelin Gem Lab. A holistic method to determining gem origin. Jewel. News Asia 2006, 264, 118-126.

12. Krzemnicki, M.S. Determining the origin of gemstones: Challenges and perspectives. InColor 2007, 4, 6-11.

13. Groat, L.A.; Giuliani, G.; Marshall, D.D.; Turner, D. Emerald deposits and occurrences: A review. Ore Geol. Rev. 2008, 34, 87-112. [CrossRef]

14. Rossman, G.R. The geochemistry of gems and its relevance to gemology: Different traces, different prices. Elements 2009, 5, 159-162. [CrossRef]

15. Nguyen Bui, H.A.; Fritsch, E.; Rondeau, B. Geographical origin: Branding or Science? InColor 2012, 19, 30-39.

16. Giuliani, G.; Groat, L.; Ohnenstetter, D.; Fallick, A.E.; Feneyrol, J. The geology of gems and their geographic origin. In Geology of Gem Deposits; Raeside, E.R., Ed.; Mineralogical Association of Canada: Tucson, AZ, USA, 2014; Volume 44, pp. 113-134.

17. Groat, L.; Giuliani, G.; Marshall, D.; Turner, D. Emerald. In Geology of Gem Deposits; Raeside, E.R., Ed.; Mineralogical Association of Canada: Tucson, AZ, USA, 2014; Volume 44, pp. 135-174.

18. Giuliani, G.; Branquet, Y.; Fallick, A.E.; Groat, L.; Marshall, D. Emerald deposits around the world, their similarities and differences. InColor 2015, 56-69.

19. Schwarz, D. The geographic origin determination of emeralds. InColor 2015, 98-105.

20. Hainschwang, T.; Notari, F. Standards and protocols for emerald analysis in gem testing laboratories. InColor 2015, 106-114.

21. Giuliani, G.; Groat, L.A.; Marshall, D.; Fallick, A.E.; Branquet, Y. Emerald Deposits: A Review and Enhanced Classification. Minerals 2019, 9, 105. [CrossRef]

22. Ogden, J.M. Rethinking laboratory reports for the geographical origin of gems. J. Gemmol. 2017, 35, 416-423. [CrossRef]

23. Cartier, L.E.; Ali, S.H.; Krzemnicki, M.S. Blockchain, chain of custody and trace elements: An overview of tracking and traceability opportunities in the gem. J. Gemmol. 2018, 36, 212-227. [CrossRef]

24. Archuleta, J.-L. The color of responsibility: Ethical issues and solutions in colored gemstones. Gems Gemol. 2016, 52, 144-160. [CrossRef] 
25. Ali, S.H.; Giurco, D.; Arndt, N.; Nickless, E.; Brown, G.; Demetriades, A.; Durrheim, R.; Enriquez, M.A.; Kinnaird, J.; Littleboy, A.; et al. Mineral supply for sustainable development requires resource governance. Nature 2017, 543, 367-372. [CrossRef] [PubMed]

26. Makki, M.; Ali, S.H. Gemstone supply chains and development in Pakistan: Analyzing the post-Taliban emerald economy in the Swat Valley. Geoforum 2019, 100, 166-175. [CrossRef]

27. Gonthier, E. The symbolic representation of famous emeralds. In L'Émeraude; Giard, D., Giuliani, G., Cheilletz, A., Fritch, E., Gonthier, E., Eds.; AFG-CNRS-ORSTOM Edition: Paris, France, 1998; pp. $27-32$.

28. Giuliani, G.; Chaussidon, M.; Schubnel, H.J.; Piat, D.; Rollion-Bard, C.; France-Lanord, C.; Giard, D.; de Narvaez, D.; Rondeau, B. Oxygen isotopes and emerald trade routes since antiquity. Science 2000, 287, 631-633. [CrossRef]

29. Calligaro, T.; Dran, J.-C.; Poirot, J.-P.; Querré, G.; Salomon, J.; Zwaan, J.C. PIXE/PIGE characterization of emeralds using an external micro-beam. Nucl. Instrum. Meth. 2000, 161-163, 769-774. [CrossRef]

30. Giuliani, G.; Chaussidon, M.; France-Lanord, C.; Guerra, H.S.; Chiappero, P.J.; Schubnel, H.J.; Gavrilenko, E.; Schwarz, D. L'exploitation des mines d'émeraude d'Autriche et de la Haute Egypte à l'époque Gallo-Romaine: Mythe ou réalité? Rev. Gemmol 2001, 143, 20-24. (In French)

31. Rondeau, B. Matériaux gemmes de référence du Museum National D’Histoire Naturelle: Exemples de valorisation scientifique d'une collection de minéralogie et gemmologie. Ph.D. Thesis, University of Nantes, Nantes, France, 2003.

32. Harrell, J.A. Archaeological geology of the world's first emerald mine. Geosci. Can. 2004, 31, 69-76.

33. Aurisicchio, C.; Corami, A.; Ehrman, S.; Graziani, G.; Cezaro, S.N. The emerald and gold necklace from Oplontis, Vesuvian Area, Naples, Italy. J. Archaeol. Sci. 2006, 33, 725-734. [CrossRef]

34. Schwarz, D.; Pardieu, V. Emeralds from the Silk Road countries. A comparison with emeralds from Colombia. InColor 2009, 12, 38-43.

35. Strack, E.; Kostov, R.I. Emeralds, sapphires, pearls and other gemmological materials from the Preslav gold treasure (X century) in Bulgaria. Geochem. Mineral. Petrol. 2010, 48, 103-123.

36. Karampelas, S.; Wörle, W.; Hunger, K.; Hanspeter, L.; Bersani, D.; Gübelin, S. Study of gems of a ciborium from Einsiedeln Abbey. Gems Gemol. 2010, 46, 291-295. [CrossRef]

37. Karampelas, S.; Wörle, W.; Hunger, K.; Hanspeter, L. Micro-Raman spectroscopy on two chalices from the Benedictine Abbey of Einsiedeln: Identification of gemstones. J. Raman Spectrosc. 2012, 43, 1833-1838. [CrossRef]

38. Farges, F.; Panczer, G.; Benbalagh, N.; Riondet, G. The Grand Sapphire of Louis XIV and The Ruspoli Sapphire. Gems Gemol. 2015, 51, 392-409.

39. Panczer, G.; Riondet, G.; Forest, L.; Krzemnicki, M.S.; Carole, D.; Faure, F. The Talisman of Charlemagne: New Historical and Gemological Discoveries. Gems Gemol. 2019, 55, 40-46. [CrossRef]

40. Aurisicchio, C.; Conte, A.M.; Medeghini, L.; Ottolini, L.; De Vito, C. Major and trace element geochemistry of emerald from several deposits: Implications for genetic models and classification schemes. Ore Geol. Rev. 2018, 94, 351-366. [CrossRef]

41. Zwaan, J.C.; Seifert, A.V.; Vrána, S.; Laurs, B.M.; Anckar, B.; Simons, W.B.S.; Falster, A.U.; Lustenhouwer, W.J.; Muhlmeister, S.; Koivula, J.K.; et al. Emeralds from the Kafubu area, Zambia. Gems Gemol. 2005, 41, 116-148. [CrossRef]

42. Saeseasaw, S.; Pardieu, V.; Sangsawong, S. Three-phase inclusions in emerald and their impact on origin determination. Gems Gemol. 2014, 50, 114-132.

43. Groat, L.A.; Laurs, B.M. Gem formation, production, and exploration: Why gem deposits are rare and what is being done to find them. Elements 2009, 5, 153-158. [CrossRef]

44. Fritsch, E.; Rondeau, B.; Devouard, B.; Pinsault, L.; Latouche, C. Why are some crystals gem quality? Crystal growth consideration on the "gem factor". Can. Mineral. 2017, 55, 521-533. [CrossRef]

45. Gramaccioli, C. Application of mineralogical techniques to gemmology. Eur J Miner. 1991, 3, $703-706$. [CrossRef]

46. Fritsch, E.; Rondeau, B. Gemology: The developing science of gems. Elements 2009, 5, 147-152. [CrossRef]

47. Devouard, B.; Notari, F. Gemstones: From the naked eye to laboratory techniques. Elements 2009, 5, 163-168. [CrossRef]

48. Karampelas, S.; Kiefert, L. Gemstones and minerals. In Analytical Archaeometry: Selected Topics, 1st ed.; Edwards, H.G.M., Vandenabeele, P., Eds.; Royal Society of Chemistry: London, UK, 2012; pp. 291-317. 
49. Gübelin, E.J.; Koivula, J.I. Photoatlas of Inclusions in Gemstones, 5th ed.; Opinio: Basel, Switzerland, 2004; Volume 1, p. 532.

50. Gübelin, E.J.; Koivula, J.I. Photoatlas of Inclusions in Gemstones; Opinio: Basel, Switzerland, 2005; Volume 2, p. 829.

51. Gübelin, E.J.; Koivula, J.I. Photoatlas of Inclusions in Gemstones; Opinio: Basel, Switzerland, 2008; Volume 3, p. 672.

52. Hänni, H.A.; Schwarz, D.; Fischer, M. The emeralds of the Belmont mine, Minas Gerais, Brazil. J. Gemmol. 1987, 53, 446-456. [CrossRef]

53. Bosshart, G. Emeralds from Colombia (Part 2). J. Gemmol. 1991, 22, 409-425. [CrossRef]

54. Bowersox, G.; Snee, L.W.; Foord, E.E.; Seal II, R.R. Emeralds of the Panjshir Valley, Afghanistan. Gems Gemol. 1991, 27, 26-39. [CrossRef]

55. Schmetzer, K.; Bernhardt, H.; Biehler, R. Emeralds from the Ural Mountains, USSR. Gems Gemol. 1991, 27, 86-99. [CrossRef]

56. Schwarz, D. Emeralds from the Mananjary region, Madagascar: Internal features. Gems Gemol. 1994, 30, 88-101. [CrossRef]

57. Zwaan, J.C.; Kanis, J.; Petsch, J. Update on emeralds from the Sandawana mines, Zimbabwe. Gems Gemol. 1997, 33, 80-101. [CrossRef]

58. Moroz, I.; Panczer, G.; Roth, M. Laser-induced luminescence of emeralds from different sources. J. Gemmol. 1998, 26, 316-320. [CrossRef]

59. Moroz, I.; Eliezri, I.Z. Mineral inclusions in emeralds from different sources. J. Gemmol. 1999, 26, $357-363$. [CrossRef]

60. Moroz, I.; Roth, M.L.; Deich, V.B. The visible absorption spectroscopy of emeralds from different deposits. Aust. Gemmol. 1999, 20, 315-320.

61. Moroz, I.; Roth, M.; Boudeulle, M.; Panczer, G. Raman microspectroscopy and fluorescence of emeralds from various deposits. J. Raman Spectrosc. 2000, 31, 485-490. [CrossRef]

62. Fritsch, E.; Rondeau, B.; Notari, F.; Michelou, J.C.; Devouard, B.; Peucat, J.J.; Chalain, J.P.; Lulzac, Y.; de Narvaez, D.; Arboleda, C. Les nouvelles mines d'émeraude de La Pita (Colombie) 2ème partie. Rev. De Gemmol. 2002, 144, 13-21. (In French)

63. Zwaan, J.C. Gemmology, geology and origin of the Sandawana emerald deposits, Zimbabwe. Scr. Geol. 2006, 131, 211.

64. Abduriyim, A.; Kitawaki, H. Applications of laser ablation-inductively coupled plasma-mass spectrometry (LA-ICP-MS) to gemology. Gems Gemol. 2006, 42, 98-118. [CrossRef]

65. Ochoa, C.J.C.; Daza, M.J.H.; Fortaleche, D.; Jiménez, J.F. Progress on the study of parameters related to the origin of Colombian emeralds. InColor 2015, 88-97.

66. Rondeau, B.; Fritsch, E.; Peucat, J.J.; Nordru, F.S.; Groat, L.A. Characterization of emeralds from a historical deposit: Byrud (Eidsvoll), Norway. Gems Gemol. 2008, 44, 108-122. [CrossRef]

67. Huong, L.T.T. Microscopic, Chemical and Spectroscopic Investigations on Emeralds of Various Origins. Ph.D. Thesis, University of Mainz, Mainz, Germany, 2008.

68. Smith, C.P.; Quinn, D.E. Inside emeralds. Rapaport Diam. Rep. 2009, 32, 139-148.

69. Huong, L.T.T.; Hager, T.; Hofmeister, W. Confocal micro-Raman spectroscopy: A powerful tool to identify natural and synthetic emeralds. Gems Gemol. 2010, 46, 139-148. [CrossRef]

70. Zwaan, J.C.; Jacob, D.E.; Häger, T.; Calvacanti Neto, M.T.O.; Kanis, J. Emeralds from the Fazenda Bonfim region, Rio Grande do Norte, Brazil. Gems Gemol. 2012, 48, 2-17. [CrossRef]

71. Cronin, D.P.; Rendle, A.M. Determining the geographical origins of natural emeralds through nondestructive chemical fingerprinting. J. Gemmol 2012, 33, 1-13. [CrossRef]

72. Bersani, D.; Azzi, G.; Lambruschi, E.; Barone, G.; Mazzoleni, P.; Raneri, S.; Longobardo, U.; Lottici, P.P. Characterization of emeralds by micro-Raman spectroscopy. J. Raman Spectrosc. 2014, 45, 1293-1300. [CrossRef]

73. Huong, L.T.T.; Hofmeister, W.; Hager, T.; Karampelas, S.; Kien, N.D.T. Identifying natural and synthetic emeralds by vibrational spectroscopy. Gems Gemol. 2014, 50, 287-292.

74. Thomson, D.B.; Kidd, J.D.; Astrom, M.; Scarani, A.; Smith, C.P. A comparison of R-line photoluminescence of emeralds from different origins. J. Gemmol. 2014, 34, 334-343. [CrossRef] 
75. Renfro, N.D.; Koivula, J.I.; Muyal, J.; McClure, S.F.; Schumacher, K.; Shigley, J.E. Chart: Inclusions in Natural, Synthetic, and Treated Emerald. Available online: https://www.gia.edu/gems-gemology/winter2016-inclusions-natural-synthetic-treated-emerald (accessed on 30 July 2019).

76. Kievlenko, E.Y. Beryl. In Geology of Gems, 1st ed.; Soregaroli, A., Ed.; Ocean Pictures Ltd.: Littleton, CO, USA, 2013; pp. 73-119.

77. Schwarz, D.; Henn, U. Emeralds from Madagascar. J. Gemmol. 1992, 23, 140-149. [CrossRef]

78. McManus, C.E.; Dowe, J.; McMillan, N.J. Quantagenetics ${ }^{\circledR}$ analysis of laser-induced breakdown spectroscopic data: Rapid and accurate authentication of materials. Spectrochim. Acta B 2018, 145, 79-85. [CrossRef]

79. Giuliani, G.; France-Lanord, C.; Zimmermann, J.-L.; Cheilletz, A.; Arboleda, C.; Charoy, B.; Coget, P.; Fontan, F.; Giard, D. Composition of fluids, $\delta \mathrm{D}$ of channel $\mathrm{H}_{2} \mathrm{O}$ and $\delta^{18} \mathrm{O}$ of lattice oxygen in beryls: Genetic implications for Brazilian, Colombian and Afghanistani emerald deposits. Int. Geol. Rev. 1997, 39, 400-424. [CrossRef]

80. Marshall, D.; Downes, P.J.; Ellis, S.; Greene, R.; Loughrey, L.; Jones, P. Pressure-temperature-fluid constraints for the Poona emerald deposits, Western Australia: Fluid inclusion and stable isotope studies. Minerals 2016, 6, 130. [CrossRef]

81. Schollenbruch, K.; Link, K.; Sintayehu, T. Gem quality emeralds from Southern Ethiopia. InColor 2017, 35, $48-54$.

82. Vertiriest, W.; Wongrawang, P.A. gemological description of Ethiopian emeralds. InColor 2018, 40, 73-75.

83. Cerny, P.; Meintzer, R.E.; Anderson, A.J. Extreme fractionation in rare-element granitic pegmatites: Selected examples of data and mechanisms. Can. Mineral. 1985, 23, 381-421.

84. London, D.; Morgan VI, G.P. The pegmatite puzzle. Elements 2012, 8, 263-268. [CrossRef]

85. Linnen, R.L.; van Lichterverlde, M.; Cerny, P.H. Granitic pegmatites as sources of strategic metals. Elements 2012, 8, 275-280. [CrossRef]

86. Simmons, W.B.; Pezzotta, F.; Shigley, J.E.; Beurlen, H. Granitic pegmatites as reflections of their sources. Elements 2012, 8, 281-287. [CrossRef]

87. Cerny, P.; London, D.; Novak, M. Granitic pegmatites as reflections of their sources. Elements 2012, 8, $289-294$. [CrossRef]

88. Wood, D.L.; Nassau, K. Characterization of beryl and emerald by visible and infrared absorption spectroscopy. Am. Mineral. 1968, 53, 777-800.

89. Platonov, A.N.; Taran, M.N.; Minko, O.E.; Polshyn, E.V. Optical absorption spectra and nature of color of iron-containing beryls. Phys. Chem. Miner. 1978, 3, 87-88.

90. Taran, M.N.T.; Rossman, G.R.R. Optical spectroscopic study and a re-examination of the beryl, cordierite, and osumilite spectra. Am. Mineral. 2001, 86, 973-980. [CrossRef]

91. Schmetzer, L. Letter: Comment on analysis of three-phase inclusions in emerald. Gems Gemol. 2014, 50, 316-319.

92. Spinolo, G.; Fontana, I.; Galli, A. Optical absorption spectra of $\mathrm{Fe}^{2+}$ and $\mathrm{Fe}^{3+}$ in beryl crystals Optical absorption spectra of $\mathrm{Fe}^{2+}$ and $\mathrm{Fe}^{3+}$ in beryl crystals. Phys. Stat. Sol. (b) 2007, 244, 4660-4668. [CrossRef]

93. Wood, D.L.; Nassau, K. Infrared spectra of foreign molecules in beryl. J. Chem Phys. 1967, 47, $2220-2228$. [CrossRef]

94. Aurisicchio, C.; Grubessi, O.; Zecchini, P. Infrared spectroscopy and crystal chemistry of the beryl group. Can. Mineral. 1994, 32, 55-68.

95. Charoy, B.; Donato, D.P.; Barres, O.; Pinto-Coelho, C. Channel occupancy in an alkali-poor beryl from Serra Branca (Goias, Brazil): Spectroscopic characterization. Am. Mineral. 1996, 81, 395-403. [CrossRef]

96. Donato, D.P.; Cheilletz, A.; Barres, O.; Yvon, J. Infrared spectroscopy of OD vibrators in minerals at natural dilution: Hydroxyl groups in talc and kaolinite, and structural water in beryl and emerald. Appl. Spectrosc. 2004, 58, 521-527. [CrossRef]

97. Adams, D.M.; Gardner, I.R. Single-crystal vibrational spectra of beryl and dioptase. J. Chem. Soc. 1974, 14, 1502-1505. [CrossRef]

98. Duroc-Danner, J.M. The identification value of the $2293 \mathrm{~cm}^{-1}$ infrared absorption band in natural and hydrothermal synthetic emeralds. J. Gemmol. 2006, 30, 75-82. [CrossRef]

99. Hagemann, H.; Lucken, A.; Bill, H.; Gysler-Sanz, J.; Stalder, H.A. Polarized Raman spectra of beryl and bazzite. Phys. Chem. Miner. 1990, 17, 395-400. [CrossRef] 
100. Kim, C.C.; Bell, M.I.; McKeown, D.A. Vibrational analysis of beryl $\left(\mathrm{Be}_{3} \mathrm{Al}_{2} \mathrm{Si}_{6} \mathrm{O}_{18}\right)$ and its constituent ring $\left(\mathrm{Si}_{6} \mathrm{O}_{18}\right)$. Phys. B. Condens. Matter 1995, 205, 193-208. [CrossRef]

101. Wood, D.L. Absorption, fluorescence, and Zeeman effect in emerald. J. Chem. Phys. 1965, 42, 3404-3410. [CrossRef]

(c) (C) 2019 by the authors. Licensee MDPI, Basel, Switzerland. This article is an open access article distributed under the terms and conditions of the Creative Commons Attribution (CC BY) license (http://creativecommons.org/licenses/by/4.0/). 